\title{
Bipyridyl-substituted benzo[1,2,3]triazoles as a thermally stable electron transporting material for organic light-emitting devices
}

Musubu Ichikawa* ${ }^{* 1,2}$, Shunji Mochizuki ${ }^{1}$, Hyeon-Gu Jeon ${ }^{1}$, Shuichi Hayashi ${ }^{3}$, Norimasa Yokoyama ${ }^{3}$, Yoshio Taniguchi ${ }^{4}$

${ }^{1}$ Functional Polymer Science Course, Division of Chemistry and Materials, Faculty of Textile Science and Technology, Shinshu University, 3-15-1 Tokida, Ueda 386-8567, Japan

${ }^{2}$ Presto, Japan Science and Technology Agency (JST), 4-8-1 Honcho, Kawaguchi, Saitama 332-0012, Japan

${ }^{3}$ Hodogaya Chemical Co., Ltd., 45 Miyukigaoka, Tsukuba, Ibaraki 305-0841, Japan

${ }^{4}$ Shinshu University, 3-15-1 Tokida, Ueda 386-8567, Japan

(received:

Abstract: We developed new electron-transporting materials (ETMs) for organic light-emitting devices (OLEDs) based on benzo[1,2,3]triazole and two bipyridines. Three derivatives based on the same skeleton were synthesized with three different substituents: phenyl (BpyBTAZ-Ph), biphenyl (-BP), m-terphenyl (-mTP), and 
o-terphenyl (-oTP). These BpyBTAZ compounds have good thermal stabilities, and their decomposition temperatures were greater than $410{ }^{\circ} \mathrm{C}$, which is significantly higher than that of tris(8-quinolinolato)aluminum (Alq), the conventional OLED material. BpyBTAZ compounds show preferable amorphous nature, and moreover, the glass transition temperatures $\left(T_{\mathrm{g}} \mathrm{s}\right)$ of both BpyBTAZ-TP compounds exceed $100{ }^{\circ} \mathrm{C}$. Furthermore, BpyBTAZ-BP exhibits no melting point and is fully amorphous. The electron affinities of the materials are as large as $3.3 \mathrm{eV}$ and their electron mobility is sufficiently high. These characteristics accounted for reduction in the operational voltage of OLEDs with BpyBTAZ compounds compared with the reference device with Alq as an ETM. Specifically, the electron mobility of all the BpyBTAZ compounds exceeds $1 \times 10^{-4} \mathrm{~cm}^{2} / \mathrm{Vs}$ at an electric field of $1 \mathrm{MV} / \mathrm{cm}$. In addition, it was revealed that both BpyBTAZ-TP-based devices showed longer luminous lifetimes and smaller voltage increases during continuous operation at $50 \mathrm{~mA} / \mathrm{cm}^{2}$, compared with the Alq reference device. 


\section{Introduction}

Organic light-emitting devices (OLEDs) are of interest for potential applications in various fields such as flat-screen televisions, mobile displays, ${ }^{1,2}$ lights, ${ }^{3}$ and optical communication light sources. ${ }^{4}$ OLEDs are usually constructed with functionally divided organic multilayers-for example, hole-transporting (HT), emissive, and electron-transporting (ET) layers. ${ }^{5,6}$ Many kinds of amorphous molecular semiconductor materials, ${ }^{7,8}$ HT materials, ${ }^{9-16}$ and ET materials (ETMs) ${ }^{17-27}$ have been proposed during the last 10 years. Among these substances, HT molecular semiconducting materials have become practical due to their high charge-carrier mobility and excellent operational durability, but few reports exist to date on ET organic semiconducting amorphous materials that perform well in terms of high-speed transport of electrons, easy injection of electrons from the cathode, and good operational durability. ${ }^{20}$ Tris (8-hydroxyquinolinato) aluminum(III) (Alq) was used in the first bright OLED reported by Tang et al. in $1987 .{ }^{5}$ Until recently, owing to its good operational durability, Alq was industrially used as an ETM despite its low electron mobility. ${ }^{28}$ However, the speed of electron feeding from the cathode into an emissive layer is one of the crucial device characteristics. Thus, the development of efficient ET organic amorphous semiconducting materials is an important objective.

1,2,4-Triazole derivatives are frequently utilized as ETMs, hole-blocking materials, host materials, and as ligands for light-emitting phosphorescent materials for OLEDs. $^{29-35}$ 1,2,4-triazole has other isomeric forms, namely, $1 \mathrm{H}-1,2,3$-triazole and 2H-1,2,3-triazole as shown in Fig. 1. Based on computational chemistry, the energies of the lowest unoccupied molecular orbital (LUMO) are $-0.65 \mathrm{eV}$ for $1 \mathrm{H}-1,2,3$-triazole, 
$-0.71 \mathrm{eV}$ for $2 \mathrm{H}-1,2,3$-triazole, and $-0.48 \mathrm{eV}$ for 1,2,4-triazole. Therefore, ETMs based on 1,2,3-triazoles appear to be a good potential for OLEDs because of their high electron affinity. Nevertheless, the reports of OLEDs based on 1,2,3-triazole derivatives are scarce-for example, phosphorescent Ir complexes containing 1H-1,2,3-triazolyl derivatives as a ligand ${ }^{36,37}$ and a bipolar host material consisting of carbazolyl and 1H-1,2,3-triazolyl groups for a blue phosphorescent light-emitter. ${ }^{38}$ As far as we know, there are no reports of $1 \mathrm{H}$ - and $2 \mathrm{H}-1,2,3$-triazole derivatives used as an ETM, and also no reports about OLED materials based on 2H-1,2,3-triazole. However, 2H-benzo[1,2,3]triazole (BTAZ)-based materials must have a good potential to be used as ETMs since 2H-1,2,3-triazole has the deepest LUMO and, moreover, a derivative group of $2 \mathrm{H}-1,2,3$-triazole, 2-(2'-hydroxyphenyl)benzo[1,2,3]triazoles, is widely utilized in polymers and plastics as an ultra-violet (UV) light absorber with a high thermal stability. Hence, we have tried to develop ETMs based on the BTAZ skeleton. We introduce bipyridyl groups to BTAZ because we have successfully produced several good ETMs based on bipyridyl-substituted compounds. ${ }^{39-41}$ In this paper we demonstrate bis(bipyridyl)-substituted 2H-benzo[1,2,3]triazole derivatives (BpyBTAZ compounds) as ETMs with high thermal stability.

\section{Experimental}

\subsection{Materials}

Scheme 1 shows chemical structures of the newly developed BpyBTAZ compounds and their synthetic routes. These materials were synthesized in the same manner except for one of the starting reactants. The first intermediate in the scheme, 
AA-Ar, was synthesized from $o$-phenylenediamine and a nitrobenzene derivative based on literature. ${ }^{42}$ The resulting AA-Ar was brominated directly in chloroform, and then Br-BTAZ-Ar was obtained by an oxidative cyclization with diacetoxyiodobenzene $\left(\mathrm{PhI}(\mathrm{OAc})_{2}\right)$ in toluene, as reported in literature. ${ }^{43}$ Br-BTAZ-Ar was changed into PinB-BTAZ-Ar by Suzuki-Miyaura coupling reaction with bis(pinacorato)diboron $\left(\operatorname{Pin}_{2} \mathrm{~B}_{2}\right)$, and then BpyBTAZ-Ar was obtained by Suzuki-Miyaura coupling reaction with 6-bromo[2,2']bipyridine, the synthesis of which was described in detail elsewhere. ${ }^{44}$ Before evaluation and measurement, the resulting BpyBTAZ compounds were purified by temperature-gradient sublimation in a flow stream of pure Ar gas. Other OLED materials were obtained from industrial sources as sublimation grades and used without further purification.

\subsection{Synthesis}

\section{4,6-Dibromo-2-phenyl-benzo[1,2,3]triazole (Br-BTAZ-Ph)}

$o$-Phenylenediamine ( $8 \mathrm{~g}, 74.0 \mathrm{mmol})$, nitrobenzene $(7.56 \mathrm{ml}, 74.0 \mathrm{mmol})$, and sodium hydroxide (3.0 g, $74.0 \mathrm{mmol}$ ) were mixed and triturated, followed by heating at $70{ }^{\circ} \mathrm{C}$ with constant scratching for $5 \mathrm{~h}$. The dark pasty mass thus obtained was cooled to room temperature and extracted with toluene. The toluene-soluble part was subjected to column chromatography on a silica gel $(\mathrm{NH}$ silica $)$ column. The third band $\left(\mathrm{R}_{\mathrm{f}}=0.7\right)$ that was eluted by a hexane-toluene mixture (1/1 v/v) was collected, and upon evaporation of the solvent, this procedure yielded $2.4 \mathrm{~g}(16.4 \%)$ of the pure 2-(phenylazo)aniline $(\mathrm{AA}-\mathrm{Ph}) . \delta_{\mathrm{H}}\left(600 \mathrm{MHz}, \mathrm{CDCl}_{3}\right): 7.84(3 \mathrm{H}, \mathrm{d}, \mathrm{J}=7.8 \mathrm{~Hz}), 7.49$ $(2 \mathrm{H}, \mathrm{dd}, \mathrm{J}=7.8 \mathrm{~Hz}), 7.42(1 \mathrm{H}, \mathrm{dd}, \mathrm{J}=7.8 \mathrm{~Hz}), 7.22(1 \mathrm{H}, \mathrm{dd}, \mathrm{J}=7.8 \mathrm{~Hz}), 6.82(1 \mathrm{H}, \mathrm{dd}$, 
$\mathrm{J}=7.2 \mathrm{~Hz}), 6.77(1 \mathrm{H}, \mathrm{d}, \mathrm{J}=8.2 \mathrm{~Hz}), 5.9(2 \mathrm{H}, \mathrm{s})$. AA-Ph $(5.7 \mathrm{~g}, 28.9 \mathrm{mmol})$ was dissolved in dry chloroform $(100 \mathrm{ml})$, bromine $(3.0 \mathrm{ml}, 58.4 \mathrm{mmol})$ in chloroform $(60$ ml) was added dropwise for $30 \mathrm{~min}$, and stirring was continued $1 \mathrm{~h}$. The $\mathrm{pH}$ of the reaction solution was adjusted to 7.0 by adding drops of aqueous solution of sodium hydrogen carbonate, and the chloroform layer was then dried $\left(\mathrm{MgSO}_{4}\right)$ and evaporated. The product $\mathrm{Br}-\mathrm{AA}-\mathrm{Ph}$ was obtained as orange flakes (9.75 g, 95\% yield) at $88 \%$ purity by high-performance liquid chromatography (HPLC). $\delta_{\mathrm{H}}\left(600 \mathrm{MHz}, \mathrm{CDCl}_{3}\right): 7.93(1 \mathrm{H}$, s), $7.84(2 \mathrm{H}, \mathrm{d}, \mathrm{J}=7.8 \mathrm{~Hz}), 7.62(1 \mathrm{H}, \mathrm{s}), 7.52(2 \mathrm{H}, \mathrm{dd}, \mathrm{J}=7.2 \mathrm{~Hz}), 7.47(1 \mathrm{H}, \mathrm{dd}, \mathrm{J}=7.2$ Hz), 6.25 (2H, s). Br-AA-Ph (7.5 g, $21.1 \mathrm{mmol})$ and $\mathrm{PhI}(\mathrm{OAc})_{2}(7.5 \mathrm{~g}, 23.3 \mathrm{mmol})$ were dissolved in toluene $(375 \mathrm{ml})$ and stirred continuously for $23 \mathrm{~h}$ at $40{ }^{\circ} \mathrm{C}$. Water $(150 \mathrm{ml})$ was added and the $\mathrm{pH}$ of the mixture was again adjusted to 7.0 by using an aqueous solution of saturated sodium sulfite. Then, the chloroform layer was dried $\left(\mathrm{MgSO}_{4}\right)$ and evaporated. The residue was solved in toluene and purified by adsorbing with $\mathrm{NH}$ silica gel. The final recrystallization from ethyl acetate gave ivory white crystal of Br-BTAZ-Ph at $5.96 \mathrm{~g}(63 \%)$ yield and $99 \%$ purity by HPLC. $\delta_{\mathrm{H}}\left(600 \mathrm{MHz}, \mathrm{CDCl}_{3}\right)$ : $8.36(2 \mathrm{H}, \mathrm{d}, \mathrm{J}=8.2 \mathrm{~Hz}), 8.07(1 \mathrm{H}, \mathrm{d}, \mathrm{J}=1.4 \mathrm{~Hz}), 7.73(1 \mathrm{H}, \mathrm{d}, \mathrm{J}=1.4 \mathrm{~Hz}), 7.57(2 \mathrm{H}, \mathrm{dd}$, $\mathrm{J}=7.6 \mathrm{~Hz}), 7.51-7.49(1 \mathrm{H}, \mathrm{m})$.

\section{BpyBTAZ-Ph}

Br-BTAZ-Ph (7.62 g, $21.6 \mathrm{mmol}), \operatorname{Pin}_{2} \mathrm{~B}_{2}(13.7 \mathrm{~g}, 53.8 \mathrm{mmol})$, potassium acetate (13.2 g, $134.4 \mathrm{mmol})$, and [1,1'-bis(diphenylphosphino)ferrocene $]$ dichloropalladium(II) $\left(\mathrm{PdCl}_{2}(\mathrm{dppf})_{2}\right)$ as catalyst were dissolved in 1,4-diozane $(160 \mathrm{ml})$. The reaction mixture was refluxed for $72 \mathrm{~h}$ at $90{ }^{\circ} \mathrm{C}$, and then cooled to room temperature. Pure water $(500 \mathrm{ml})$ was added, and the mixture was stirred for $30 \mathrm{~min}$ and 
filtered to remove precipitates. Black crude crystalline powder was obtained by extraction using ethyl acetate and evaporation. The crude was dissolved in toluene-ethyl acetate mixed solvent $(1 / 1 \mathrm{v} / \mathrm{v})$ and then purified by adsorbing with silica gel. Evaporation and hexane washing gave a gray crystalline solid of PinB-BTAZ-Ph at 7.6 g $(70 \%)$ yield and $92 \%$ purity by HPLC. $\delta_{\mathrm{H}}\left(600 \mathrm{MHz}, \mathrm{CDCl}_{3}\right): 8.56(1 \mathrm{H}, \mathrm{s}), 8.42(2 \mathrm{H}$, d, J = 7.8 Hz), $8.30(1 \mathrm{H}, \mathrm{s}), 7.55(2 \mathrm{H}, \mathrm{dd}, \mathrm{J}=8.4 \mathrm{~Hz}), 7.44(1 \mathrm{H}, \mathrm{dd}, \mathrm{J}=7.2 \mathrm{~Hz}), 1.45$ $(13 \mathrm{H}, \mathrm{s}), 1.39(13 \mathrm{H}, \mathrm{s})$. BpyBTAZ-Ph was synthesized from PinB-BTAZ-Ph (4.0 g, $8.95 \mathrm{mmol})$ and Br-Bpy (5.0 g, $22.4 \mathrm{mmol})$ by Suzuki-Miyaura coupling reaction using $2 \mathrm{M} \quad \mathrm{K}_{2} \mathrm{CO}_{3}$ aqueous solution $(13.4 \mathrm{ml}, 26.8 \mathrm{mmol})$ as base, tetrakis(trisphenylphosphine)palladium(0) $(0.52 \mathrm{~g}, 0.45 \mathrm{mmol})$ as catalyst, and $200 \mathrm{ml}$ of a 1/4 ethanol/toluene mixture as solvent. The reaction mixture was refluxed with stirring for $5 \mathrm{~h}$ and then cooled to room temperature. Precipitations appeared and were collected by filtration, and then washed with pure water and toluene. A final wash with acetonitrile under reflux produced $4.7 \mathrm{~g}(85 \%)$ of a greenish white crystal of BpyBTAZ-Ph at $99 \%$ purity by HPLC. $\delta_{\mathrm{H}}\left(600 \mathrm{MHz}, \mathrm{CDCl}_{3}\right): 9.60(1 \mathrm{H}, \mathrm{d}, \mathrm{J}=2.1 \mathrm{~Hz})$, $8.98(1 \mathrm{H}, \mathrm{d}, \mathrm{J}=7.6 \mathrm{~Hz}), 8.83-8.79(3 \mathrm{H}, \mathrm{m}), 8.74(2 \mathrm{H}, \mathrm{t}, \mathrm{J}=4.1 \mathrm{~Hz}), 8.51-8.48(4 \mathrm{H}, \mathrm{m})$, 8.08-8.04 (2H, m), $8.00(1 \mathrm{H}, \mathrm{dd}, \mathrm{J}=7.6 \mathrm{~Hz}), 7.87(2 \mathrm{H}, \mathrm{td}, \mathrm{J}=7.6,2.1 \mathrm{~Hz}), 7.62(2 \mathrm{H}$, $\mathrm{dd}, \mathrm{J}=7.9 \mathrm{~Hz}), 7.51(1 \mathrm{H}, \mathrm{dd}, \mathrm{J}=7.2 \mathrm{~Hz}), 7.38-7.36(2 \mathrm{H}, \mathrm{m})$.

\section{BpyBTAZ-BP}

BpyBTAZ-BP was synthesized by the same route as BpyBTAZ-Ph except for using 2-nitrobiphenyl instead of nitrobenzene to obtain a corresponding azo intermediate. $o$-Phenylenediamine $(9.1 \mathrm{~g}, 83.8 \mathrm{mmol})$, 2-nitrobiphenyl $(16.7 \mathrm{~g}, 83.8$ mmol), sodium hydroxide $(5.57 \mathrm{~g}, 117.5 \mathrm{mmol})$, and toluene $(35 \mathrm{~mL})$ were mixed and 
triturated, followed by heating under refluxing with constant scratching for $17 \mathrm{~h}$. The reaction mixture was cooled to room temperature and poured into a saturated $\mathrm{NaCl}$ aqueous solution. The obtained precipitation was filtered and extracted with toluene. The toluene-soluble part was subjected to column chromatography on a silica gel column. The third band $\left(\mathrm{R}_{\mathrm{f}}=0.3\right)$ that was eluted by a hexane-toluene mixture $(3 / 4 \mathrm{v} / \mathrm{v})$ was collected, and upon evaporation of the solvent yielded 2-(2'-biphenylazo)aniline (AA-BP) $(6.94 \mathrm{~g}, 31 \%$ yield $)$ at $97 \%$ purity by $\mathrm{HPLC} . \delta_{\mathrm{H}}\left(600 \mathrm{MHz}, \mathrm{CDCl}_{3}\right): 8.30(1 \mathrm{H}$, $\mathrm{d}, \mathrm{J}=7.8 \mathrm{~Hz}), 8.11(1 \mathrm{H}, \mathrm{d}, \mathrm{J}=6.0 \mathrm{~Hz}), 7.5-7.4(5 \mathrm{H}, \mathrm{m}), 7.41(2 \mathrm{H}, \mathrm{t}, \mathrm{J}=7.2 \mathrm{~Hz}), 6(1 \mathrm{H}$, d, J = 7.2 Hz), $7.13(1 \mathrm{H}, \mathrm{dd}, \mathrm{J}=8.3 \mathrm{~Hz}), 6.78(1 \mathrm{H}, \mathrm{dd}, 8.4 \mathrm{~Hz}), 6.60(1 \mathrm{H}, \mathrm{d}, \mathrm{J}=8.4 \mathrm{~Hz})$ $5.80(2 \mathrm{H}, \mathrm{s})$. AA-BP $(15.0 \mathrm{~g}, 54.9 \mathrm{mmol})$ was dissolved in dry chloroform (200 ml), and bromine $(6.8 \mathrm{ml}, 131.8 \mathrm{mmol})$ in chloroform $(100 \mathrm{ml})$ was added dropwise for $30 \mathrm{~min}$, and the mixture was stirred continuously for $5 \mathrm{~h}$. Water $(100 \mathrm{~mL})$ was added, and the chloroform layer was then dried $\left(\mathrm{MgSO}_{4}\right)$ and evaporated. The residue (dark pasty mass) was subjected to column chromatography on a silica gel column. The second band $\left(\mathrm{R}_{\mathrm{f}}=0.5\right)$ that was eluted by a chloroform-hexane mixture $(1 / 3 \mathrm{v} / \mathrm{v})$ was collected, and upon evaporation of the solvent yielded 2-(2'-biphenylazo)4,6-dibromoaniline (Br-AA-BP) $\left(9.90 \mathrm{~g}, 42.6 \%\right.$ yield) at a purity of $96 \%$ by HPLC. $\delta_{\mathrm{H}}\left(600 \mathrm{MHz}, \mathrm{CDCl}_{3}\right)$ : $7.93(1 \mathrm{H}, \mathrm{s}), 7.82(1 \mathrm{H}, \mathrm{d}, \mathrm{J}=7.2 \mathrm{~Hz}), 7.55(1 \mathrm{H}, \mathrm{s}), 7.52(2 \mathrm{H}, \mathrm{d}, \mathrm{J}=4.2 \mathrm{~Hz}), 7.5-7.4(6 \mathrm{H}$, m), $6.33(2 \mathrm{H}, \mathrm{s})$. Br-AA-BP (11.7 g, $27.1 \mathrm{mmol})$ and $\mathrm{PhI}(\mathrm{OAc})_{2}(8.7 \mathrm{~g}, 27.1 \mathrm{mmol})$ were dissolved in toluene $(300 \mathrm{ml})$ and stirred continuously for $7 \mathrm{~h}$ at $60{ }^{\circ} \mathrm{C}$. Water $(200$ $\mathrm{mL}$ ) was added and the $\mathrm{pH}$ of the mixture was adjusted to 7.5 by adding soda ash. Then, the toluene layer was dried $\left(\mathrm{MgSO}_{4}\right)$ and evaporated. The residue was subjected to column chromatography on a silica gel column. The fourth band $\left(\mathrm{R}_{\mathrm{f}}=0.3\right)$ that was eluted by a chloroform-hexane mixture $(1 / 3 \mathrm{v} / \mathrm{v})$ was collected, and upon evaporation 
of the solvent yielded 2-(2'-biphenylazo)-4,6-dibromo-2H-benzotriazole (Br-BTAZ-BP) $\left(10.5 \mathrm{~g}, 91 \%\right.$ yield) at $95 \%$ purity by HPLC. $\delta_{\mathrm{H}}\left(600 \mathrm{MHz}, \mathrm{CDCl}_{3}\right)$ : $7.91(1 \mathrm{H}, \mathrm{s}), 7.76(1 \mathrm{H}, \mathrm{d}, \mathrm{J}=7.2 \mathrm{~Hz}), 7.68(1 \mathrm{H}, \mathrm{s}), 7.63(1 \mathrm{H}, \mathrm{t}, \mathrm{J}=7.2 \mathrm{~Hz}), 7.58(1 \mathrm{H}, \mathrm{d}$, $\mathrm{J}=6.6 \mathrm{~Hz}), 7.55(1 \mathrm{H}, \mathrm{t}, \mathrm{J}=8.4 \mathrm{~Hz}), 7.23-7.19(3 \mathrm{H}, \mathrm{m}), 7.06(2 \mathrm{H}, \mathrm{d}, \mathrm{J}=7.2 \mathrm{~Hz})$. Br-BTAZ-Ph (10.5 g, $25.4 \mathrm{mmol}), \operatorname{Pin}_{2} \mathrm{~B}_{2}(15.5 \mathrm{~g}, 61.0 \mathrm{mmol})$, potassium acetate (15.0 g, $152.4 \mathrm{mmol})$, and the catalyst $\mathrm{PdCl}_{2}(\mathrm{dppf})_{2}$ were dissolved in 1,4-diozane $(250 \mathrm{~mL})$. The reaction mixture was refluxed for $7 \mathrm{~h}$ at $90{ }^{\circ} \mathrm{C}$ and then cooled to room temperature. Pure water $(500 \mathrm{ml})$ was added, and the mixture was stirred for $30 \mathrm{~min}$ and filtered to remove precipitates. A black crude pasty mass was obtained by extraction using chloroform and evaporation. The crude mass was dissolved in ethyl acetate and then purified by adsorption on silica gel. Evaporation and hexane washing produced PinB-BTAZ-BP as a greenish white crystalline solid $(8.6 \mathrm{~g}, 66 \%$ yield $)$ at $93 \%$ purity by HPLC. $\delta_{\mathrm{H}}\left(600 \mathrm{MHz}, \mathrm{CDCl}_{3}\right): 8.42(1 \mathrm{H}, \mathrm{s}), 8.25(1 \mathrm{H}, \mathrm{s}), 7.86(1 \mathrm{H}, \mathrm{d}, \mathrm{J}=7.2 \mathrm{~Hz}),(3 \mathrm{H}$, m), 7.14(3H, m), $7.05(2 \mathrm{H}, \mathrm{d}, \mathrm{J}=7.2 \mathrm{~Hz}), 1.36(26 \mathrm{H}, \mathrm{d}, \mathrm{J}=5 \mathrm{~Hz})$. BpyBTAZ-BP was synthesized from PinB-BTAZ-BP (4.0 g, $6.90 \mathrm{mmol})$ and Br-Bpy (3.8 g, $17.3 \mathrm{mmol})$ by the Suzuki-Miyaura coupling reaction using $2 \mathrm{M} \mathrm{K}_{2} \mathrm{CO}_{3}$ aqueous solution (10.4 ml, $20.7 \mathrm{mmol})$ as base, tetrakis(trisphenylphosphine)palladium(0) $(0.40 \mathrm{~g}, 0.35 \mathrm{mmol})$ as catalyst, and $200 \mathrm{ml}$ of a $1 / 4$ ethanol/toluene mixture as solvent. The reaction mixture was refluxed with stirring for $6 \mathrm{~h}$ and then cooled to room temperature. Water (1000 $\mathrm{mL})$ was poured onto the mixture and the toluene layer was dried $\left(\mathrm{MgSO}_{4}\right)$ and evaporated. The residue was subjected to column chromatography on a silica gel column. The third band $\left(\mathrm{R}_{\mathrm{f}}=0.5\right)$ that was eluted by chloroform was collected, and upon evaporation of the solvent yielded BpyBTAZ-BP (3.2 g, 73\% yield) at 98\% purity by HPLC. $\delta_{\mathrm{H}}\left(600 \mathrm{MHz}, \mathrm{DMSO}-\mathrm{d}_{6}\right): 9.60(1 \mathrm{H}, \mathrm{s}), 8.85(1 \mathrm{H}, \mathrm{s}), 8.75(2 \mathrm{H}, \mathrm{d}, \mathrm{J}=3.4 \mathrm{~Hz})$, 
$8.68(2 \mathrm{H}, \mathrm{dd}, \mathrm{J}=8.6 \mathrm{~Hz}), 8.42-8.41(2 \mathrm{H}, \mathrm{m}), 8.31(1 \mathrm{H}, \mathrm{d}, \mathrm{J}=6.9 \mathrm{~Hz}), 8.16(1 \mathrm{H}, \mathrm{d}, \mathrm{J}=$ $8.9 \mathrm{~Hz}), 8.10(1 \mathrm{H}, \mathrm{dd}, \mathrm{J}=7.9 \mathrm{~Hz}), 8.06(1 \mathrm{H}, \mathrm{d}, \mathrm{J}=4.5 \mathrm{~Hz}), 7.99-7.98(3 \mathrm{H}, \mathrm{m}), 7.80(1 \mathrm{H}$, $\mathrm{dd}, \mathrm{J}=7.2 \mathrm{~Hz}), 7.75-7.72(2 \mathrm{H}, \mathrm{m}), 7.53-7.52(2 \mathrm{H}, \mathrm{m}), 7.30-7.27(3 \mathrm{H}, \mathrm{m}), 7.15(2 \mathrm{H}, \mathrm{d}, \mathrm{J}$ $=6.9 \mathrm{~Hz})$. Mass spectrum: 580.44 and isotopes $(100 \%)\left([\mathrm{M}+\mathrm{H}]^{+} ; 579.22\right.$ for $\mathrm{M}$ : $\mathrm{C}_{36} \mathrm{H}_{25} \mathrm{~N}_{7}$ ) after sublimation purification.

\section{BpyBTAZ-mTP}

BpyBTAZ-mTP was synthesized by almost the same procedure as BpyBTAZ-BP except for the following: $5^{\prime}$-nitro[1,1';3',1']terphenyl was used instead of nitrobenzene to obtain a corresponding intermediate, toluene was removed from the reaction mixture using the Dean-Stark apparatus at the initial stage of the reaction, and the reaction conditions were $140{ }^{\circ} \mathrm{C}$ for $8 \mathrm{~h} .{ }^{45}$ The resulting BpyBTAZ-mTP was pale yellow with the following characteristics: $\delta_{\mathrm{H}}\left(600 \mathrm{MHz}, \mathrm{CDCl}_{3}\right): 9.56(1 \mathrm{H}, \mathrm{s}), 8.92(1 \mathrm{H}$, $\mathrm{d}, \mathrm{J}=7.2 \mathrm{~Hz}), 8.80(3 \mathrm{H}, \mathrm{d}, \mathrm{J}=8.4 \mathrm{~Hz}), 8.74-8.73(2 \mathrm{H}, \mathrm{m}), 8.67(2 \mathrm{H}, \mathrm{s}), 8.49(2 \mathrm{H}, \mathrm{dd}, \mathrm{J}$ $=7.8 \mathrm{~Hz}, 9.0 \mathrm{~Hz}), 8.06(1 \mathrm{H}, \mathrm{dd}, \mathrm{J}=7.8 \mathrm{~Hz}), 8.01(1 \mathrm{H}, \mathrm{d}, \mathrm{J}=7.8 \mathrm{~Hz}), 7.97(1 \mathrm{H}, \mathrm{dd}, \mathrm{J}=$ $7.8 \mathrm{~Hz}), 7.91(1 \mathrm{H}, \mathrm{s}), 7.84-7.81(6 \mathrm{H}, \mathrm{m}), 7.54(4 \mathrm{H}, \mathrm{dd}, \mathrm{J}=7.8 \mathrm{~Hz}), 7.48(2 \mathrm{H}, \mathrm{dd}, \mathrm{J}=7.8$ $\mathrm{Hz}), 7.37(2 \mathrm{H}, \mathrm{dd}, \mathrm{J}=5.4 \mathrm{~Hz})$. Mass spectrum: 655.96 and isotopes $(100 \%)\left([\mathrm{M}+\mathrm{H}]^{+}\right.$; 655.25 for $\mathrm{M}: \mathrm{C}_{44} \mathrm{H}_{29} \mathrm{~N}_{7}$ ) after sublimation purification.

AA-mTP: $\delta_{\mathrm{H}}\left(600 \mathrm{MHz}, \mathrm{CDCl}_{3}\right): 8.05(2 \mathrm{H}, \mathrm{s}), 7.88(1 \mathrm{H}, \mathrm{d}, \mathrm{J}=10.2 \mathrm{~Hz}), 7.87(1 \mathrm{H}, \mathrm{s})$, $7.73(4 \mathrm{H}, \mathrm{d}, \mathrm{J}=7.8 \mathrm{~Hz}), 7.50(4 \mathrm{H}, \mathrm{dd}, \mathrm{J}=7.8 \mathrm{~Hz}), 7.41(2 \mathrm{H}, \mathrm{dd}, \mathrm{J}=7.8 \mathrm{~Hz}), 7.24(2 \mathrm{H}$, m) $6.84(1 \mathrm{H}, \mathrm{dd}, \mathrm{J}=7.8 \mathrm{~Hz}), 6.79(1 \mathrm{H}, \mathrm{d}, \mathrm{J}=7.8 \mathrm{~Hz}), 5.98(2 \mathrm{H}, \mathrm{s})$

Br-AA-mTP: $\delta_{\mathrm{H}}\left(600 \mathrm{MHz}, \mathrm{CDCl}_{3}\right): 8.03(2 \mathrm{H}, \mathrm{s}), 7.98(1 \mathrm{H}, \mathrm{s}), 7.91(1 \mathrm{H}, \mathrm{s}), 7.71(4 \mathrm{H}, \mathrm{d}$, $\mathrm{J}=7.2 \mathrm{~Hz}), 7.63(1 \mathrm{H}, \mathrm{s}), 7.50(4 \mathrm{H}, \mathrm{dd}, \mathrm{J}=7.8 \mathrm{~Hz}), 7.42(2 \mathrm{H}, \mathrm{dd}, \mathrm{J}=6 \mathrm{~Hz}), 6.34(2 \mathrm{H}, \mathrm{s})$ 
Br-BTAZ-mTP: $\delta_{\mathrm{H}}\left(600 \mathrm{MHz}, \mathrm{CDCl}_{3}\right): 8.56(2 \mathrm{H}, \mathrm{s}), 8.08(1 \mathrm{H}, \mathrm{s}), 7.92(1 \mathrm{H}, \mathrm{s}), 7.76$ $(4 \mathrm{H}, \mathrm{d}, \mathrm{J}=7.2 \mathrm{~Hz}), 7.74(1 \mathrm{H}, \mathrm{s}), 7.52(4 \mathrm{H}, \mathrm{d}, \mathrm{J}=7.2 \mathrm{~Hz}), 7.45(2 \mathrm{H}, \mathrm{d}, \mathrm{J}=7.8 \mathrm{~Hz})$

PinB-BTAZ-mTP: $\delta_{\mathrm{H}}\left(600 \mathrm{MHz}, \mathrm{CDCl}_{3}\right): 8.63(2 \mathrm{H}, \mathrm{s}), 8.59(1 \mathrm{H}, \mathrm{s}), 8.33(1 \mathrm{H}, \mathrm{s}), 7.88$ $(1 \mathrm{H}, \mathrm{s}), 7.78(4 \mathrm{H}, \mathrm{d}, \mathrm{J}=7.2 \mathrm{~Hz}), 7.54(4 \mathrm{H}, \mathrm{dd}, \mathrm{J}=8.4 \mathrm{~Hz}), 7.44(2 \mathrm{H}, \mathrm{d}, \mathrm{J}=7.8 \mathrm{~Hz}), 1.46$ $(12 \mathrm{H}, \mathrm{s}), 1.40(12 \mathrm{H}, \mathrm{s})$

BpyBTAZ-oTP

BpyBTAZ-oTP was synthesized by the same route as BpyBTAZ-mTP except for using $2^{\prime}$-nitro[1, $\left.1^{\prime} ; 3^{\prime}, 1^{\prime \prime}\right]$ terphenyl instead of nitrobenzene to obtain a corresponding intermediate. The resulting BpyBTAZ-oTP was white with the following characteristics: $\delta_{\mathrm{H}}\left(600 \mathrm{MHz}, \mathrm{CDCl}_{3}\right): 9.31(1 \mathrm{H}, \mathrm{s}), 8.74-8.73(4 \mathrm{H}, \mathrm{m}), 8.57(1 \mathrm{H}, \mathrm{s})$, 8.44-8.41 (2H, m), 7.96-7.96 (2H, m), $7.92(1 \mathrm{H}, \mathrm{d}, \mathrm{J}=7.2 \mathrm{~Hz}), 7.85$ (1H, d, J = 7.2 Hz), $7.83(2 \mathrm{H}, \mathrm{dd}, \mathrm{J}=7.8 \mathrm{~Hz}), 7.73(1 \mathrm{H}, \mathrm{dd}, \mathrm{J}=7.2 \mathrm{~Hz}), 7.64(2 \mathrm{H}, \mathrm{d}, \mathrm{J}=7.8 \mathrm{~Hz}), 7.35(2 \mathrm{H}$, $\mathrm{dd}, \mathrm{J}=7.8 \mathrm{~Hz}), 7.14-7.14(10 \mathrm{H}, \mathrm{m})$. Mass spectrum: 655.94 and isotopes $(100 \%)$ $\left([\mathrm{M}+\mathrm{H}]^{+} ; 655.25\right.$ for $\left.\mathrm{M}: \mathrm{C}_{44} \mathrm{H}_{29} \mathrm{~N}_{7}\right)$ after sublimation purification.

AA-oTP: $\delta_{\mathrm{H}}\left(600 \mathrm{MHz}, \mathrm{CDCl}_{3}\right): 7.51(1 \mathrm{H}, \mathrm{dd}, \mathrm{J}=6.6 \mathrm{~Hz}), 7.45(2 \mathrm{H}, \mathrm{d}, \mathrm{J}=7.8 \mathrm{~Hz}), 7.34(4 \mathrm{H}$, m), $7.27(6 \mathrm{H}, \mathrm{m}) 7.05(1 \mathrm{H}, \mathrm{dd}, \mathrm{J}=7.2 \mathrm{~Hz}), 6.91(1 \mathrm{H}, \mathrm{d}, \mathrm{J}=7.8 \mathrm{~Hz}), 6.63(1 \mathrm{H}, \mathrm{d}, \mathrm{J}=8.4 \mathrm{~Hz})$, $6.42(1 \mathrm{H}, \mathrm{dd}, \mathrm{J}=7.2 \mathrm{~Hz}), 5.75(2 \mathrm{H}, \mathrm{s})$

Br-AA-oTP: $\delta_{\mathrm{H}}\left(600 \mathrm{MHz}, \mathrm{CDCl}_{3}\right): 7.66(1 \mathrm{H}, \mathrm{s}), 7.58(1 \mathrm{H}, \mathrm{dd}, \mathrm{J}=7.8 \mathrm{~Hz}), 7.50(2 \mathrm{H}, \mathrm{d}, \mathrm{J}=$ $7.8 \mathrm{~Hz}), 7.37(4 \mathrm{H}, \mathrm{dd}, \mathrm{J}=7.2 \mathrm{~Hz}), 7.25(6 \mathrm{H}, \mathrm{d}, \mathrm{J}=7.8 \mathrm{~Hz}), 7.02(1 \mathrm{H}, \mathrm{s})$

Br-BTAZ-oTP: $\delta_{\mathrm{H}}\left(600 \mathrm{MHz}, \mathrm{CDCl}_{3}\right): 7.82(1 \mathrm{H}, \mathrm{s}) 7.69(1 \mathrm{H}, \mathrm{dd}, \mathrm{J}=7.8 \mathrm{~Hz}), 7.57(1 \mathrm{H}, \mathrm{s}$,$) ,$ $7.55(2 \mathrm{H}, \mathrm{d}, \mathrm{J}=7.2 \mathrm{~Hz}), 7.10-7.26(10 \mathrm{H}, \mathrm{m})$

PinB-BTAZ-oTP: $\delta_{\mathrm{H}}\left(600 \mathrm{MHz}, \mathrm{CDCl}_{3}\right): 8.15(1 \mathrm{H}, \mathrm{s}), 7.97(1 \mathrm{H}, \mathrm{s}), 7.86(1 \mathrm{H}, \mathrm{t}, \mathrm{J}=8.4 \mathrm{~Hz})$, $7.66(2 \mathrm{H}, \mathrm{d}, \mathrm{J}=7.8 \mathrm{~Hz}) 7.13-7.06(10 \mathrm{H}, \mathrm{m}), 1.34(12 \mathrm{H}, \mathrm{m}), 1.30(12 \mathrm{H}, \mathrm{m})$ 


\subsection{Device Fabrication and Measurements}

All OLEDs were fabricated on 150-nm-thick layers of indium-tin oxide (ITO) that were commercially pre-coated onto glass substrates with a sheet resistance of 14 $\Omega /$ sq. The solvent-cleaned ITO surface was treated with a UV ozone cleaner for $15 \mathrm{~min}$ and then the substrate was immediately loaded into a high-vacuum chamber (base pressure below $2 \times 10^{-4} \mathrm{~Pa}$ ) where organic layers, 0.5 -nm-thick LiF, and 200-nm-thick aluminum cathode layers were deposited by thermal evaporation. Deposition rates were $0.6 \AA / \mathrm{s}$ for organic materials, $0.1 \AA / \mathrm{s}$ for $\mathrm{LiF}$, and $6 \AA / \mathrm{s}$ for Al. The structure of the devices fabricated in this study is shown in Figure 2. The current density-applied voltage-luminance $(J-V-L)$ characteristics of the OLEDs were measured with a commercial OLED-characteristics measurement system (Precise Gauge EL1003) and a source meter (Keithley 2400). Electroluminescence (EL) spectra were recorded simultaneously with the EL1003 during the $J-V-L$ measurements.

${ }^{1} \mathrm{H}$ and ${ }^{13} \mathrm{C}$ NMR spectra were recorded on a Fourier transform (FT)-NMR spectrometer (JEOL JNM-ECA600). Mass spectroscopic analysis was carried out with a matrix-assisted laser desorption ionization (MALDI) time-of-flight (TOF) mass spectrometer (Bruker Daltonics Autoflex) with no internal standard. Thermal analyses were performed on a differential scanning calorimeter (Seiko Instruments DSC-6200) and a thermogravimeter/differential thermal analyzer (Bruker AXS TG/DTA 2000S) at a heating rate of $10^{\circ} \mathrm{C} / \mathrm{min}$ under $\mathrm{N}_{2}$ gas. UV and visible absorption spectra were recorded with a spectrophotometer (Shimadzu UV-3150); photoluminescence (fluorescence and phosphorescence) spectra were recorded with a spectrofluorometer 
(Horiba FluoroMax4P). Ionization potential $\left(I_{\mathrm{p}}\right)$ was determined with a photoelectron emission yield spectrometer (Riken Keiki AC-3). Optical band gaps were determined by the spectral onset of each UV-visible absorption spectrum; electron affinity $\left(E_{\mathrm{a}}\right)$ was then estimated by subtracting the band gap from $I_{\mathrm{p}}$. Spectroscopic measurements were conducted with thin films prepared by thermal evaporation on quartz substrates. We also determined the densities of the thin films prepared on Si wafers by thermal evaporation by using X-ray reflectometry with a Rigaku SmartLab.

Electron mobility was measured by conventional TOF techniques. The excitation light was a 500-ps-duration optical pulse from a $\mathrm{N}_{2}$ gas laser $(\lambda=337 \mathrm{~nm}$, Lasertechnik Berlin MNL 200). Test samples were prepared by thermal evaporation in vacuum and encapsulated with fresh desiccant under a highly inert atmosphere of $\mathrm{N}_{2}$ at the dew point of almost $-60^{\circ} \mathrm{C}$ and an $\mathrm{O}_{2}$ concentration of $<5$ ppm. A 100 -nm-thick fullerene $C_{60}$ layer was used as a charge-generation layer for optical excitation ${ }^{40}$. The structure of TOF samples is shown in Fig. 2(c).

Computational chemistry was conducted using commercial software (Wavefunction Spartan 08W) on a personal computer with a dual-core processer. Density function theory (DFT) was used to determine conformations, with a B3LYP hybrid functional and a $6-311+\mathrm{G}^{* *}$ basis set for determining optimized geometries and their energies.

\section{Results and Discussion}

\subsection{Thermal and Electronic Properties}


Figure 3 shows thermogravimetry (TG) and differential scanning calorimetry (DSC) curves of BpyBTAZ compounds. Decomposition temperatures $\left(T_{\mathrm{d}}\right)$ with 5\%-weight loss were $418{ }^{\circ} \mathrm{C}$ for BpyBTAZ-Ph, $422{ }^{\circ} \mathrm{C}$ for -BP, $479{ }^{\circ} \mathrm{C}$ for -mTP, and $440{ }^{\circ} \mathrm{C}$ for -oTP, respectively. These $T_{\mathrm{d}}$ values indicate that BpyBTAZ compounds can be continuously evaporated for a long time with less byproducts due to decomposition during vacuum evaporations. In fact, as shown in the figure, the $T_{\mathrm{d}}$ values of BpyBTAZ compounds was higher than that of Alq $\left(366^{\circ} \mathrm{C}\right)$, one of the most conventional OLED materials. The evaporation temperatures of the BpyBTAZ compounds in vacuum evaporators are important when discussing thermal stability. However, instead of the evaporation temperature, we list the heater temperature of each BpyBTAZ compound in the sublimation purification process: $200{ }^{\circ} \mathrm{C}$ for BpyBTAZ-P, $230{ }^{\circ} \mathrm{C}$ for $-\mathrm{BP}, 300{ }^{\circ} \mathrm{C}$ for -mTP, and $230{ }^{\circ} \mathrm{C}$ for -oTP. These values are smaller or almost the same compared with that $\left(305^{\circ} \mathrm{C}\right)$ obtained for Alq using the same experimental setup. In addition, the figure also shows the TG curve of bipyridyl-substituted $4 \mathrm{H}-1,2,4$-triazole, ${ }^{41}$ whose IUPAC name is 2-(1-naphthyl)-6-[4-phenyl-5-[6-(2-pyridyl)-2-pyridyl]-1,2,4-triazol-3-yl]pyridine (BpyTAZ-03). We consider this 1,2,4-triazole to be a good ET and hole-blocking material with high electron mobility for both fluorescent and phosphorescent OLEDs. ${ }^{41}$ The $T_{\mathrm{d}}$ of this $1,2,4$-triazole was $394.0{ }^{\circ} \mathrm{C}$. The improved $T_{\mathrm{d}}$ values of BpyBTAZ compounds compared with the 1,2,4-triazole is caused by the high thermal stability of benzo[1,2,3]trizole.

DSC curves of BpyBTAZ compounds in the figure indicate that all BpyBTAZ compounds can form amorphous glassy thin films because glass transition behaviors could be observed in the second heating after quick cooling at the rate of $-50{ }^{\circ} \mathrm{C} / \mathrm{min}$. 
That is, we can find the baseline shifts at $78{ }^{\circ} \mathrm{C}$ for BpyBTAZ-Ph, $91{ }^{\circ} \mathrm{C}$ for BpyBTAZ-BP, $107{ }^{\circ} \mathrm{C}$ for BpyBTAZ-mTP, and $117{ }^{\circ} \mathrm{C}$ for BpyBTAZ-oTP, respectively. BpyBTAZ-oTP exhibited the highest glass transition temperature $\left(T_{\mathrm{g}}\right)$ of $117^{\circ} \mathrm{C}$ among all BpyBTAZ compounds, probably, because of the larger molecular weight and bulkiness of the substituent at the $2^{\text {nd }}$ position of BTAZ. Surprisingly, BpyBTAZ, whose conformation can be assumed to be almost planar as shown in Fig. 4(a), has an amorphous character. Usually, planar aromatic molecules are crystalline and rarely form amorphous glassy thin films. We believe that the asymmetric substitutions of bipyridines to BTAZ might prevent crystallization and cause the amorphous character. In addition, the geometry of BpyBTAZ-Ph shown in Fig. 4(b) is the second lowest, and the energy difference is only $0.07 \mathrm{~kJ} / \mathrm{mol}$. This small energy difference can enable mixing of the two conformations in quenched (rapid cooling) solids and also in evaporated thin films. This mixing probably also results in amorphous nature as reported in literature. ${ }^{40,41}$ Note that BpyBTAZ-BP showed no $T_{\mathrm{m}}$ but exhibited $T_{\mathrm{g}}$ even in the first heating. This means that BpyBTAZ-BP is a perfectly amorphous material. The thermal properties of BpyBTAZ compounds are summarized in Table 1. Note that the densities of BpyBTAZ compounds in thin-film state increased with increase in molecular weight. This straightforward result probably implies that the molecular geometries of BpyBTAZ compounds are independent of the introduced substituents.

Figure 5 shows the UV-visible absorption and fluorescence spectra of BpyBTAZ compounds in their thin-film state. The figure also shows the phosphorescence spectrum of BpyBTAZ-oTP in 2-methyltetrahydrofuran at $77 \mathrm{~K}$. All BpyBTAZ compounds show optical absorption onset at a wavelength of about $400 \mathrm{~nm}$ and pure blue to sky blue 
fluorescence that peaked at $410 \mathrm{~nm}$ to $480 \mathrm{~nm}$. Band gaps $\left(E_{\mathrm{g}}\right)$ of the materials were estimated from the onsets of the optical absorption spectra and then summarized in Table 1. The $E_{\mathrm{g}}$ values were as large as $3 \mathrm{eV}$, and the $I_{\mathrm{p}}$ values that were determined using photoemission electron yield spectroscopy varied from 6.2 to $6.5 \mathrm{eV}$. The resulting $E_{\mathrm{a}}$ values, estimated by subtracting each $E_{\mathrm{g}}$ from each $I_{\mathrm{p}}$, were almost the same (about $3.3 \mathrm{eV}$ ). This findings suggest that the lowest unoccupied molecular orbital (LUMO) of each BpyBTAZ probably is localized in the bis(bipyridyl)benzo[1,2,3]triazole unit, but each of the highest occupied molecular orbital (HOMO) appears to be in the BTAZ ring while each substituent is joined at the second nitrogen atom. This is because the phenyl ring occupies the same plane as the BTAZ ring with respect to the absence of steric hindrance between the phenyl ring and the triazole. On the other hand, the blue-shifted fluorescence spectra and absorption onsets of BpyBTAZ-BP and -oTP (resulting in the wider $E_{\mathrm{g}}$ and larger $I_{\mathrm{p}}$ shown in Table 1) implies that its molecular geometry should twist at the single bond connecting the BTAZ ring with biphenyl or terphenyl due to strong steric hindrance of another ortho-linked phenyl ring. The large $E_{\mathrm{a}}$ values of the materials can be effective for electron injection from the cathode, resulting in reduction of operational voltage. The relatively deep $I_{\mathrm{p}}$ values probably affect hole-blocking but we did not investigate this relationship.

Figure 5 also shows the phosphorescence spectrum of BpyBTAZ-oTP, which has the largest triplet energy in the materials. The phosphorescence was observed in the red region while the fluorescence occurs in the blue region even in solid state, and the energy difference between the first excited singlet $\left(\mathrm{S}_{1}\right)$ and triplet $\left(\mathrm{T}_{1}\right)$ states was large. In general, the energy difference between $S_{1}$ and $T_{1}$ is caused by exchange interaction of 
the two unpaired electrons, either in the HOMO or the LUMO, and then each distribution of the HOMO and LUMO in a molecule. In other words, spatial overlap of both orbitals strongly affects the energy of interaction. The large energy differences between $\mathrm{S}_{1}$ and $\mathrm{T}_{1}$ of all the BTAZ compounds imply that the HOMOs and LUMOs of the materials largely overlap each other, resulting in consistency with the abovementioned discussion of distribution of their HOMOs and LUMOs.

\subsection{OLED Performance}

Figure 6(a) presents $J-V$ curves of the devices with each BpyBTAZ. The devices with BpyBTAZ compounds showed lower operational voltage than the reference device without BpyBTAZ. Specifically, the devices with BpyBTAZ-mTP nd -oTP exhibited a very low operational voltage and a current density of $7.5 \mathrm{~mA} / \mathrm{cm}^{2}$ at a voltage of $3.0 \mathrm{~V}$. In addition, the current density of the devices with both BpyBTAZ-TP rapidly increased with a small boost of applied voltage, and reached $100 \mathrm{~mA} / \mathrm{cm}^{2}$ at just $4.2 \mathrm{~V}$ for $-\mathrm{mTP}$ and $4.3 \mathrm{~V}$ for $-\mathrm{oTP}$, respectively. This low operational voltage strongly implies that BpyBTAZ-mTP and -oTP probably possesses both a good electron injection property from the cathode and high electron mobility. The relatively large $E_{\mathrm{a}} \mathrm{S}$ of BpyBTAZ compounds probably caused this good electron injection from the cathode. The variation of the operational voltages of the devices with BpyBTAZ compounds indicate that the electron mobilities of BpyBTAZ-Ph and -BP would be smaller than those of BpyBTAZ-mTP and -oTP.

Figure 6(b) shows luminous efficiency-current density $(\eta-J)$ characteristics of the devices with each BpyBTAZ. The luminous efficiencies of the devices with BpyBTAZ compounds were slightly lower than the reference. The EL spectrum of the 
BpyBTAZ-mTP device shown in the inset of the figure indicates that recombination of both charge carriers (electron and hole) should occur in the Alq layer; this is also true for the devices with other BpyBTAZ compounds (see Fig. S2 in the supporting information). Note that no other EL peak was presented even when observed at high magnification (see inset of Fig. 6b). However, the device showed a lower luminous efficiency. This decrease is probably caused by interactions at the heterointerfaces of NPB/Alq and/or Alq/BpyBTAZ. In accordance with Matsumoto et al. ${ }^{46}$ HTLs with Ip < $5.7 \mathrm{eV}$ cause exciplex-like interactions that reduce the luminescence yield of Alq in its excited state. Figure 6(b) also shows the $\eta-J$ curve of another device in which a bilayer combination of 1,1-bis( $N$-biphenyl- $N$-phenylaminophenyl)cyclohexane (TPD-012) $\begin{array}{lllllll}\text { having } & \mathrm{a} & \text { deeper } & I_{\mathrm{p}} & \text { of } & 5.7 & \mathrm{eV}\end{array}$ 4,4'-bis(diphenylanilino-4"'-yl) $N, N, N^{\prime}, N^{\prime}$-tetraphenylbenzidine (TPT-1) was used as an HTM instead of NPB. ${ }^{47}$ The luminous efficiency for a current of $4.1 \mathrm{~cd} / \mathrm{A}$ was almost the same as that for standard Alq-emissive layer devices while its onset voltage $\left(V_{\mathrm{ON}}\right)$ obtained at a current density of $5 \mathrm{~mA} / \mathrm{cm}^{2}$ was $3.1 \mathrm{~V}$. This is higher than the $V_{\mathrm{ON}}(2.8 \mathrm{~V})$ of the original device using NPB as the HTM (see Fig. S3 in the supporting information) and lower than the $V_{\mathrm{ON}}(3.9 \mathrm{~V})$ of the reference device with Alq as the ETM and TPD-012/TPT-1 as the HTM. We infer that the small increase of $V_{\mathrm{ON}}$ in the TPD-012/TPT-1 device compared with the original device (difference of $0.3 \mathrm{~V}$ ) arises due to the small HOMO gap of $0.3 \mathrm{eV}$ at the interface between TPD-012 and TPT-1. Therefore, it can be assumed that a recombination zone at the HTL/Alq interface caused the lower luminous efficiencies of the devices with BpyBTAZ compounds, which could achieve low operational voltage. This means that BpyBTAZ compounds have high electron mobility. 


\subsection{Electron Mobility}

Finally, we would like to discuss briefly the electron mobility in the new materials. Figure 7 shows, on a double logarithmic scale, the transient electron photocurrent waveform obtained by TOF measurements for the BpyBTAZ-mTP film whose thickness is $5.2 \mu \mathrm{m}$. Although each photocurrent waveform looks non-dispersive, we could clearly see that the transits of photogenerated charge carriers-electrons in this case- become faster with increased applied voltages because the photocurrents decayed more rapidly. In accordance with the conventional method of transit time $\left(t_{\mathrm{T}}\right)$ determination for dispersive transportations, we drew two auxiliary straight lines as shown in the figure and determined the $t_{\mathrm{T}}$ at the crossing point of these auxiliary lines. Note that the slopes of the auxiliary lines for each photocurrent are similar, and this also supports the assumption that the observed photocurrents are due to drift motions in the film. If we take electron mobility $\mu$ to be

$$
\mu=\frac{D d}{t_{T} V}
$$

where $D$ is the distance between the two electrodes $(5.3 \mu \mathrm{m}), d$ is the thickness of the prepared BpyBTAZ-mTP layer $(5.2 \mu \mathrm{m})$, and $V$ is the applied voltage, we can determine, for example, that $\mu=3.28 \times 10^{-4} \mathrm{~cm}^{2} / \mathrm{Vs}$ at an electric field $E=V / D=1.02 \times$ $10^{6} \mathrm{~V} / \mathrm{cm}$. This mobility is two orders of magnitude higher than that for Alq $\left(3.3 \times 10^{-6}\right.$ $\mathrm{cm}^{2} / \mathrm{Vs}$ ) at approximately the same electric field. ${ }^{48}$ This high mobility probably accounts for a better $J-V$ curve for the OLED with BpyBTAZ-mTP compared to that for the OLED with the corresponding reference. Figure 8 shows electron mobility as a function of the square root of the applied electric field for several materials, including BpyBTAZ compounds. Both BpyBTAZ-Ph, -mTP, and -oTP show mobility that is at 
least two orders of magnitude higher than that of Alq. This high mobility is comparable to that of a representative ET material with high electron mobility, such as a silole derivative, 2,5-bis(6'-(2',2'-bipyridine) $)$-1,1-dimethyl-3,4-diphenylsilole (PyPySiPyPy). ${ }^{48,49}$ Almost the same mobility of BpyBTAZ-Ph, -mTP, and -oTP indicate that the BpyBTAZ unit transport electron. On the other hand, while only BpyBTAZ-BP showed inferior mobility compared with the other BpyBTAZ compounds, we have no sufficient physical and/or chemical insight of it at present. The full amorphous nature of BpyBTAZ-BP might affect it.

\subsection{Durability}

Figure 9 shows the normalized luminance and voltage changes under constant current density operation at $50 \mathrm{~mA} / \mathrm{cm}^{2}$ (an accelerated condition) of the three devices with different ETMs: BpyBTAZ-mTP, -oTP, and Alq. The luminance of the devices with BpyBTAZ compounds hardly decrease compared to that of the Alq reference device. The devices for this test were fabricated at the university, and it is well known that operation durability of OLEDs strongly depend on the quality of device fabrication including substrate cleaning processes and encapsulation of the devices. Consequently, it is difficult to determine the exact lifetimes of the test devices but it is clear that the two BpyBTAZ compounds improve the durability of OLEDs. The lower operation voltages of the BpyBTAZ-based devices might offer better operation durability; and the smaller voltage changes in these devices compared with Alq devices support this speculation. We infer that the smaller electron injection barrier due to the deeper LUMO and/or high electron mobility of BpyBTAZ compounds gives rise to smaller voltage increases. As the decomposition temperatures of the BpyBTAZ compounds are high, 
the BpyBTAZ-based devices have less impurities and this could also contribute to their durability.

\section{Summary}

We have developed new ETM compounds for OLEDs based on benzo[1,2,3]triazole and asymmetrically substituted two bipyridines. The materials, BpyBTAZ compounds, have good thermal stabilities and their decomposition temperatures are greater than $410{ }^{\circ} \mathrm{C}$, which is higher than that $\left(366^{\circ} \mathrm{C}\right)$ of Alq, the conventional OLED material. Since benzo[1,2,3]triazole derivatives are well known as UV absorbers with high thermal stability, BpyBTAZ compounds also probably possess high thermal stabilities. BpyBTAZ compounds exhibit a preferable amorphous nature, and, specifically, the $T_{\mathrm{g}} \mathrm{S}$ of both BpyBTAZ-TP compounds exceed $100{ }^{\circ} \mathrm{C}$. Furthermore, BpyBTAZ-BP exhibits no melting point and is fully amorphous. The electron affinities of the materials are as large as $3.3 \mathrm{eV}$, and the electron mobility of these materials are sufficiently high. These characteristics accounted for a reduction in the operational voltage of OLEDs with BpyBTAZ compounds compared with the reference device with Alq as ETM. The mobility of all the BpyBTAZ compounds exceeded $1 \times 10^{-4} \mathrm{~cm}^{2} /$ Vs at an electric field of $1 \mathrm{MV} / \mathrm{cm}$. The devices with both BpyBTAZ-TP compounds require just 4.2 or $4.3 \mathrm{~V}$ for $100 \mathrm{~mA} / \mathrm{cm}^{2}$, a sufficiently large current density. In addition, the two BpyBTAZ-TP-based devices showed longer luminous lifetimes and smaller voltage increases than the Alq reference device. This study is the first report of $2 \mathrm{H}-1,2,3$-triazole as an OLED material, and we clearly demonstrated that bipyridine-substituted benzo[1,2,3]triazoles, which is one of derivatives of 2H-1,2,3-triazole, must be useful as ETMs for OLEDs. 


\section{Acknowledgments}

The authors would like to thank Prof. Dr. M. Kimura for mass spectroscopic measurements. The authors would like to thank Riken Keiki and Rigaku for $I_{\mathrm{p}}$ and density measurements. 


\section{References}

1 J.-h. Choi, K.-H. Kim, S.-J. Choi and H. H. Lee, Nanotechnology, 2006, 17, 2246.

2 Y. Nakajima, T. Takei, T. Tsuzuki, M. Suzuki, H. Fukagawa, T. Yamamoto and S. Tokito, J. Soc. Inform. Display, 2009, 17, 629-634.

3 K. T. Kamtekar, A. P. Monkman and M. R. Bryce, Adv. Mater., 2010, 22, 572-582.

4 Y. Ohmori, Laser \& Photonics Reviews, 2010, 4, 300-310.

5 C. W. Tang and S. A. VanSlyke, Appl. Phys. Lett., 1987, 51, 913-915.

6 C. Adachi, T. Tsutsui and S. Saito, Appl. Phys. Lett., 1990, 57, 531-533.

7 Y. Shirota, J. Mater. Chem., 2000, 10, 1-25.

8 U. Mitschke and P. Baeuerle, J. Mater. Chem., 2000, 10, 1471 - 1507.

9 S. A. VanSlyke, C. H. Chen and C. W. Tang, Appl. Phys. Lett., 1996, 69, $2160-2162$.

10 M. Thelakkat and H.-W. Schmidt, Adv. Mater., 1998, 10, 219-223.

11 K. Katsuma and Y. Shirota, Adv. Mater., 1998, 10, 223-226.

12 H. Tanaka, S. Tokito, Y. Taga and A. Okada, Chem. Commun., 1996, 2175-2178.

13 M. Ichikawa, K. Hibino, N. Yokoyama, T. Miki, T. Koyama and Y. Taniguchi, Synth. Met., 2006, 156, 1383-1389.

14 Y.-L. Liao, W.-Y. Hung, T.-H. Hou, C.-Y. Lin and K.-T. Wong, Chem. Mater., 2007, 19, 6350-6357.

15 C.-Y. Lin, Y.-M. Chen, H.-F. Chen, F.-C. Fang, Y.-C. Lin, W.-Y. Hung, K.-T. Wong, R. C. Kwong and S. C. Xia, Org. Electron., 2009, 10, 181-188.

16 Z. Jiang, Z. Liu, C. Yang, C. Zhong, J. Qin, G. Yu and Y. Liu, Adv. Funct. Mater., 2009, 19, 3987-3995. 
17 C. Adachi, T. Tsutsui and S. Saito, Appl. Phys. Lett., 1989, 55, 1489.

18 Y. Hamada, C. Adachi, T. Tsutsui and S. Saito, Jpn. J. Appl. Phys., 1992, 31, $1812-1816$.

19 K. Tamao, M. Uchida, T. Izumizawa, K. Furukawa and S. Yamaguchi, J. Am. Chem. Soc., 1996, 118, 11974-11975.

20 M. Uchida, T. Izumizawa, T. Nakano, S. Yamaguchi, K. Tamao and K. Furukawa, Chem. Mater., 2001, 13, 2680-2683.

21 J. Bettenhausen and P. Strohriegl, Adv. Mater., 1996, 8, 507-810.

22 S. B. Heidenhain, Y. Sakamoto, T. Suzuki, A. Miura, H. Fujikawa, T. Mor, S. Tokito and Y. Taga, J. Am. Chem. Soc., 2000, 122, 10240-10241.

23 G. Hughes and M. R. Bryce, J. Mater. Chem., 2005, 15, 94-107.

24 Y.-J. Pu, M. Yoshizaki, T. Akiniwa, K.-i. Nakayama and J. Kido, Org. Electron., 2009, 10, 877-882.

25 H. Sasabe, E. Gonmori, T. Chiba, Y.-J. Li, D. Tanaka, S.-J. Su, T. Takeda, Y.-J. Pu, K.-i. Nakayama and J. Kido, Chem. Mater., 2008, 20, 5951-5953.

26 H. Tsuji, K. Sato, Y. Sato and E. Nakamura, J. Mater. Chem., 2009, 19, 3364-3366.

27 L. Na, W. Pengfei, L. Shiu-Lun, L. Weimin, L. Chun-Sing, L. Shuit-Tong and L. Zengtao, Adv. Mater., 2010, 22, 527-530.

28 R. G. Kepler, P. M. Beeson, S. J. Jacobs, R. A. Anderson, M. B. Sinclair, V. S. Valencia and P. A. Cahill, Appl. Phys. Lett., 1995, 66, 3618-3620.

29 J. Kido, C. Ohtaki, K. Hongawa, K. Okuyama and K. Nagai, Jpn. J. of Appl. Phys., 1993, 32, L917-L920.

30 C. Adachi, M. A. Baldo, S. R. Forrest and M. E. Thompson, Appl. Phys. Lett., 2000, 77, 904-906. 
31 Z. H. Li, M. S. Wong, H. Fukutani and Y. Tao, Organic Letters, 2006, 8, 4271-4274.

32 T. W. Canzler and J. Kido, Org. Electron., 2006, 7, 29-37.

33 C. W. Joo, K. S. Yook, S. O. Jeon and J. Y. Lee, Org. Electron., 2009, 10, 978-981.

34 Y. Tao, Q. Wang, L. Ao, C. Zhong, C. Yang, J. Qin and D. Ma, J. Phys. Chem. C, 2009, 114, 601-609.

35 C.-H. Chang, K.-C. Tien, C.-C. Chen, M.-S. Lin, H.-C. Cheng, S.-H. Liu, C.-C. Wu, J.-Y. Hung, Y.-C. Chiu and Y. Chi, Org. Electron., 2010, 11, 412-418.

36 E. Orselli, G. S. Kottas, A. E. Konradsson, P. Coppo, R. Froehlich, L. De Cola, A. van Dijken, M. Buechel and H. Boerner, Inorg Chem, 2007, 46, 11082-11093.

37 E. Orselli, R. Q. Albuquerque, P. M. Fransen, R. Frohlich, H. M. Janssen and L. D. Cola, J. Mater. Chem., 2008, 18, 4579-4590.

38 M. K. Kim, J. Kwon, T.-H. Kwon and J.-I. Hong, New J. Chem., 2010, 34, 1317-1322.

39 M. Ichikawa, T. Kawaguchi, K. Kobayashi, T. Miki, K. Furukawa, T. Koyama and Y. Taniguchi, J. Mater. Chem., 2006, 16, 221-225.

40 M. Ichikawa, N. Hiramatsu, N. Yokoyama, T. Miki, S. Narita, T. Koyama and Y. Taniguchi, Phys. Status Solidi (RRL), 2007, 1, R37-R39.

41 M. Ichikawa, S. Fujimoto, Y. Miyazawa, T. Koyama, N. Yokoyama, T. Miki and Y. Taniguchi, Org. Electron., 2008, 9, 77-84.

42 N. Maiti, S. Pal and S. Chattopadhyay, Inorg Chem, 2001, 40, 2204-2205.

43 L. K. Dyall, J. J. Harvey and T. B. Jarman, Aust J Chem, 1992, 45, 371-384.

44 M. Ichikawa, K. Wakabayashi, S. Hayashi, N. Yokoyama, T. Koyama and Y. Taniguchi, Org. Electron., 2010, 11, 1966-1973. 
45 The temperature is higher than melting point of 1,2-phenylenediamine $\left(105^{\circ} \mathrm{C}\right)$.

46 N. Matsumoto and C. Adachi, J. Phys. Chem. C, 2010, 114, 4652-4658.

47 Device structure is $\quad$ ITO/TPT-1(40 nm)/TPD-012(10 nm)/Alq(20 nm)/BpyBTAZ-TP(30 nm)/LiF(0.5 nm)/Al.

48 H. Murata, G. G. Malliaras, M. Uchida, Y. Shen and Z. H. Kafafi, Chem. Phys. Lett., 2001, 339, 161-166.

49 S. Tabatake, S. Naka, H. Okada, H. Onnagawa, M. Uchida, T. Nakano and K. Furukawa, Jpn. J. of Appl. Phys., 2002, 41, 6582-6585. 
Table 1. Basic properties of BpyBTAZ compounds. $T_{\mathrm{m}}, T_{\mathrm{g}}$, and $T_{\mathrm{d}}$ were measured in their solid state. All other properties except for triplet energy $\left(E_{\mathrm{T}}\right)$ were measured in their thin-film state. $E_{\mathrm{T}}$ was estimated from its methyltetrahydrofuran solution at $77 \mathrm{~K}$.

Scheme 1. Synthetic route of BpyBTAZ compounds.

Figure 1. LUMO and HOMO energies of the three isomers of triazole.

Figure 2. Structures of devices and chemicals used in this study.

Figure 3. (a) TG and (b) DSC curves of BpyBTAZ compounds. Dotted lines in panel (b) show vertically 5-times-magnified curves around the temperature range of each $\mathrm{Tg}$. The DSC curves were measured in the second heating at a heating rate of $10{ }^{\circ} \mathrm{C} / \mathrm{min}$ after rapid cooling.

Figure 4. Optimized geometries of BpyBTAZ-Ph with the lowest (a) and the second-lowest (b) energies. The bipyridine on the left of the BTAZ ring in the lowest geometry (a) was almost coplanar with the BTAZ ring, whose dihedral angle was $11.0^{\circ}$, because there was no steric hindrance of the hydrogen atoms at each ortho-position. However, the dihedral angle between the BTAZ ring and the other bipyridine was $24.9^{\circ}$ due to the steric hindrance of the pair of the hydrogen atoms at the other ortho-positions. The energy difference between the two geometries was $0.07 \mathrm{~kJ} / \mathrm{mol}$. 
Figure 5. UV-visible absorption and PL spectra of BpyBTAZ compounds in their thin-film states. The figure also shows the phosphorescence spectrum of BpyBTAZ-BP in 2-methyltetrahydrofuran at a temperature of $77 \mathrm{~K}$.

Figure 6. (a) Current density-voltage $(J-V)$ and (b) luminous efficiency-current density $(\eta-J)$ curves of devices with each BpyBTAZ. The inset in panel (b) shows the EL spectrum of the BpyBTAZ-mTP device and the dotted line is a $\times 10$ magnification.

Figure 7. Transient photocurrent curves of TOF measurement of BpyBTAZ-mTP at the applied voltages of 450 and $540 \mathrm{~V}$. Red straight lines are drawn to help determine the transit time.

Figure 8. Electron mobilities of BpyBTAZ compounds as a function of square root of electric field. Data for Alq were referred from the literature by Murata (see text).

Figure 9. Luminance and voltage changes under constant current density operation at 50 $\mathrm{mA} / \mathrm{cm}^{2}$ for devices with different ETMs. The device structure is the same as the test OLED shown in Fig. 2. The devices were encapsulated by a glass cap with fresh desiccant using UV glue in an inert glove box $\left(\mathrm{O}_{2}<5\right.$ ppm, dewpoint $\left.<-50{ }^{\circ} \mathrm{C}\right)$. 
Table 1. Basic properties of BpyBTAZ compounds. $T_{\mathrm{m}}, T_{\mathrm{g}}$, and $T_{\mathrm{d}}$ were measured in their solid state. All other properties except for triplet energy $\left(E_{\mathrm{T}}\right)$ were measured in their thin-film state. $E_{\mathrm{T}}$ was estimated from its methyltetrahydrofuran solution at $77 \mathrm{~K}$.

\begin{tabular}{ccccccccc}
\hline Material & $T_{\mathrm{m}}\left({ }^{\circ} \mathrm{C}\right)$ & $T_{\mathrm{g}}\left({ }^{\circ} \mathrm{C}\right)$ & $T_{\mathrm{d}}\left({ }^{\circ} \mathrm{C}\right)$ & $\begin{array}{c}\text { Density } \\
\left(\mathrm{g} / \mathrm{cm}^{3}\right)\end{array}$ & $I_{\mathrm{p}}(\mathrm{eV})$ & $E_{\mathrm{a}}(\mathrm{eV})$ & $E_{\mathrm{g}}(\mathrm{eV})$ & $E_{\mathrm{T}}(\mathrm{eV})$ \\
\hline BpyBTAZ-Ph & 224 & 78 & 418 & 1.20 & 6.23 & 3.25 & 2.98 & 2.03 \\
BpyBTAZ-BP & n.d. & 91 & 422 & 1.22 & 6.50 & 3.36 & 3.14 & 2.08 \\
BpyBTAZ-mTP & 249 & 107 & 479 & 1.24 & 6.35 & 3.33 & 3.02 & 2.03 \\
BpyBTAZ-oTP & 231 & 117 & 440 & $\mathrm{ND}$ & 6.51 & 3.27 & 3.24 & 2.14 \\
\hline
\end{tabular}

ND: not determined 


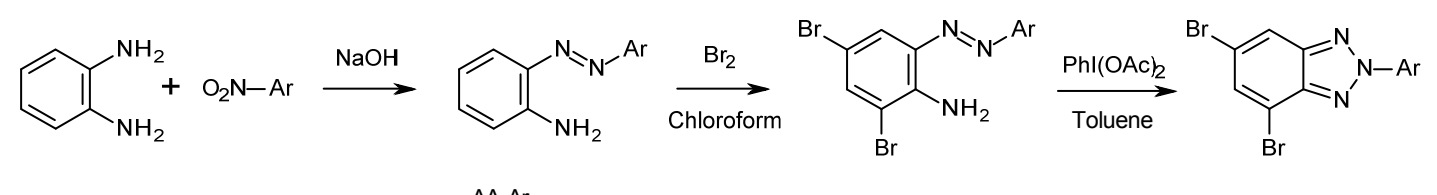
AA-Ar Br-AA-Ar Br-BTAZ-Ar

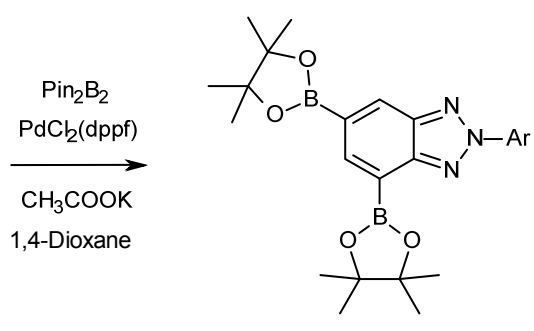

PinB-BTAZ-Ar

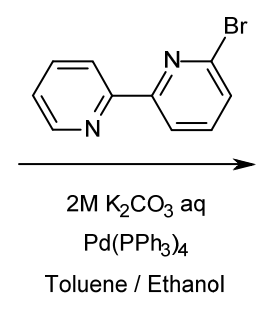<smiles>CCc1cc(-c2ccccc2)cc(-c2ccccc2)c1</smiles>

mTP<smiles>CCc1c(-c2ccccc2)cccc1-c1ccccc1</smiles>

oTP

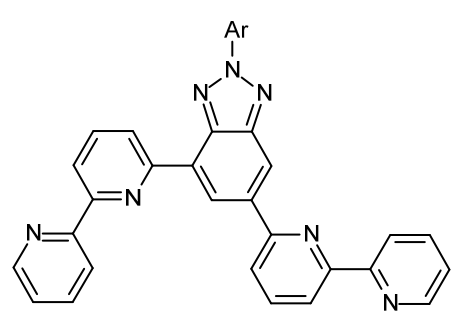

BpyBTAZ-Ar
$\operatorname{Ar}=$<smiles>CC(C)c1ccccc1</smiles>

$\mathrm{Ph}$<smiles>CC(C)c1ccccc1-c1ccccc1</smiles>

$\mathrm{BP}$

Scheme 1. Synthetic route of BpyBTAZ compounds. 


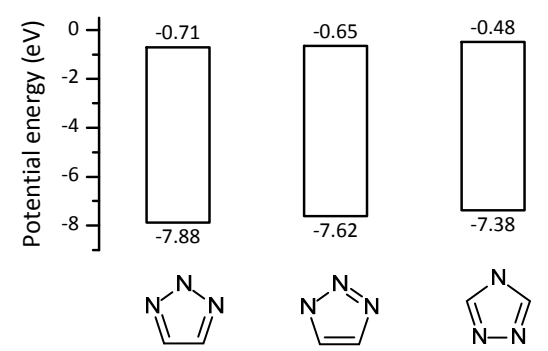

Figure 1. LUMO and HOMO energies of the three isomers of triazole. 

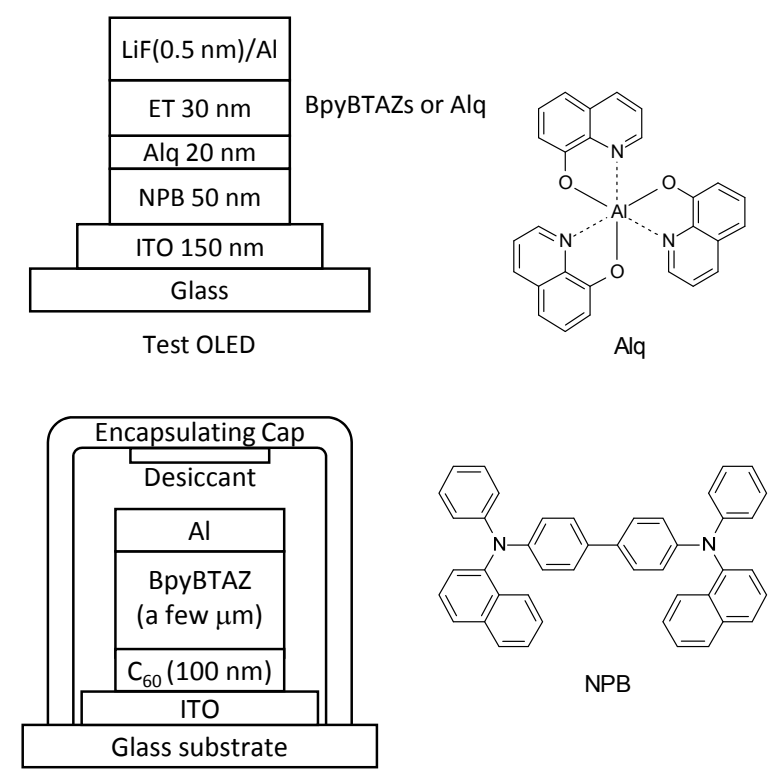

TOF device

Figure 2. Structures of devices and chemicals used in this study. 

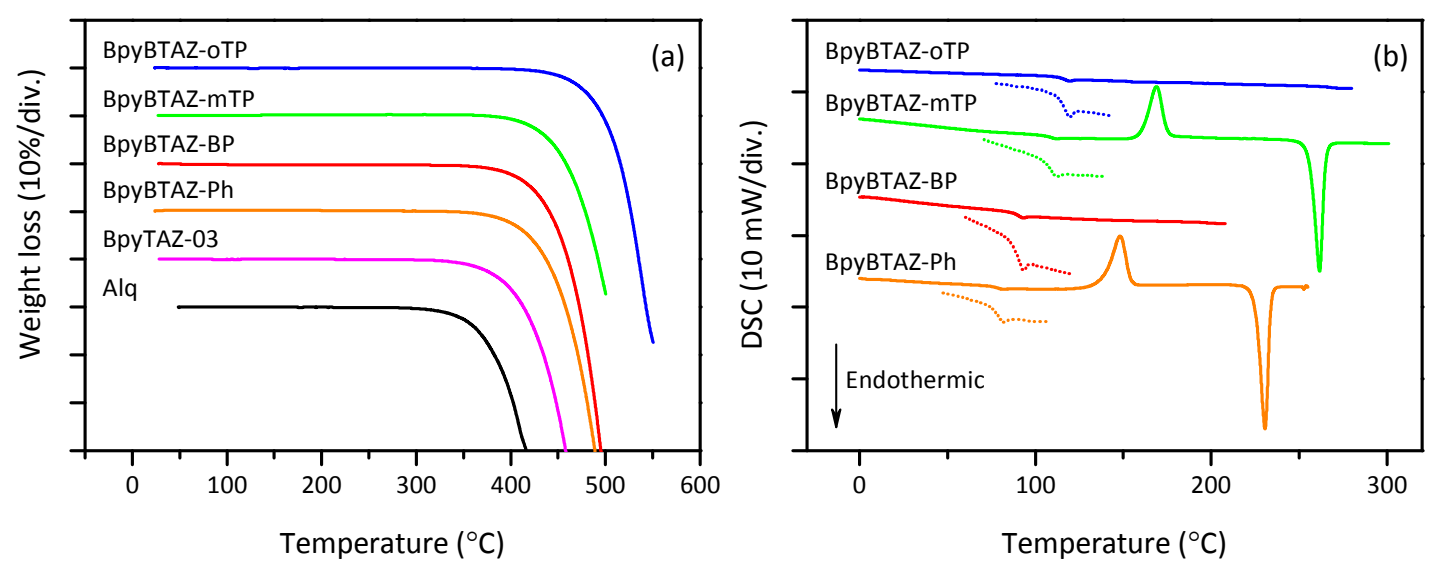

Figure 3. (a) TG and (b) DSC curves of BpyBTAZ compounds. Dotted lines in panel (b) show vertically 5-times-magnified curves around the temperature range of each $\mathrm{Tg}$. The DSC curves were measured in the second heating at a heating rate of $10{ }^{\circ} \mathrm{C} / \mathrm{min}$ after rapid cooling. 
(a)

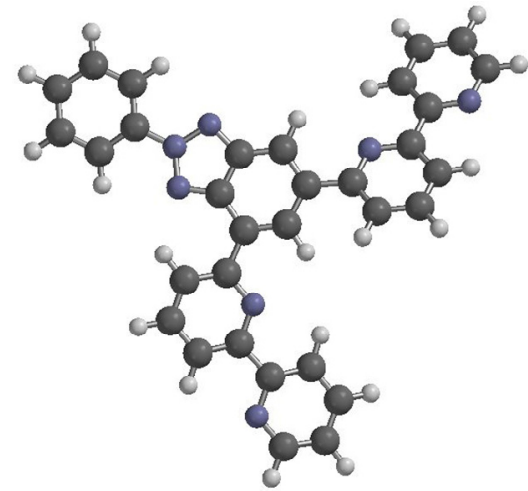

(b)

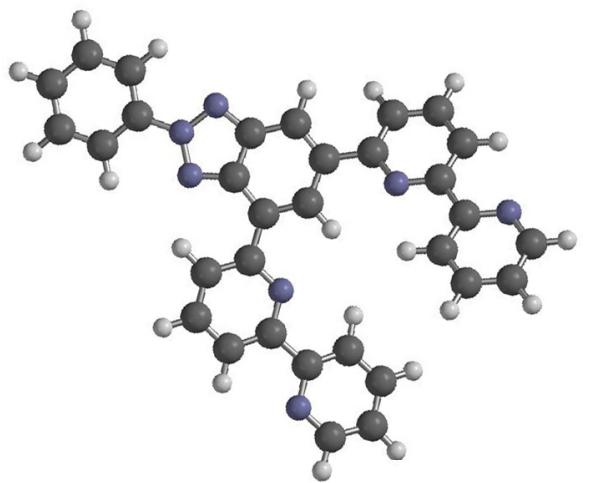

Figure 4. Optimized geometries of BpyBTAZ-Ph with the lowest (a) and the second-lowest (b) energies. The bipyridine on the left of the BTAZ ring in the lowest geometry (a) was almost coplanar with the BTAZ ring, whose dihedral angle was $11.0^{\circ}$, because there was no steric hindrance of the hydrogen atoms at each ortho-position. However, the dihedral angle between the BTAZ ring and the other bipyridine was $24.9^{\circ}$ due to the steric hindrance of the pair of the hydrogen atoms at the other ortho-positions. The energy difference between the two geometries was $0.07 \mathrm{~kJ} / \mathrm{mol}$. 


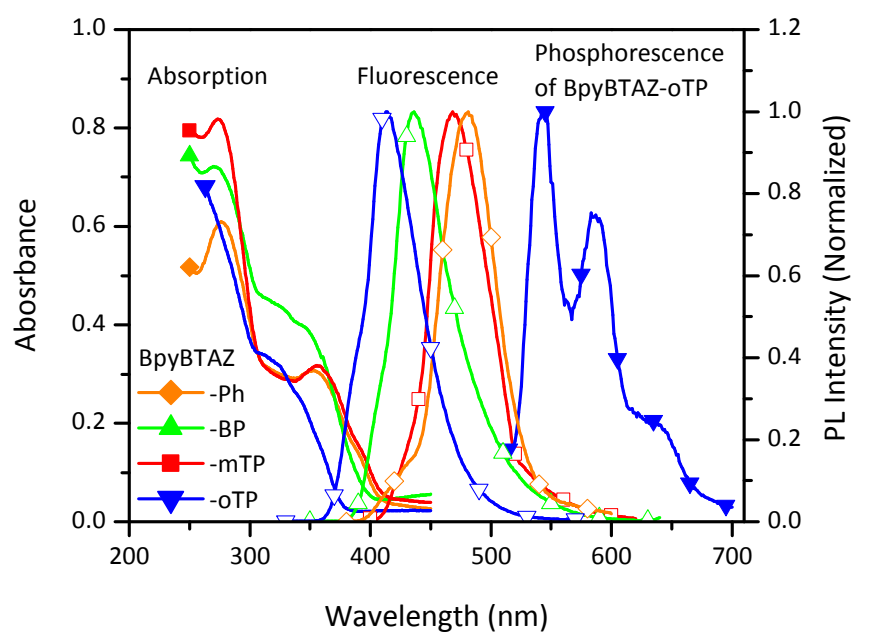

Figure 5. UV-visible absorption and PL spectra of BpyBTAZ compounds in their thin-film states. The figure also shows the phosphorescence spectrum of BpyBTAZ-BP in 2-methyltetrahydrofuran at a temperature of $77 \mathrm{~K}$. 

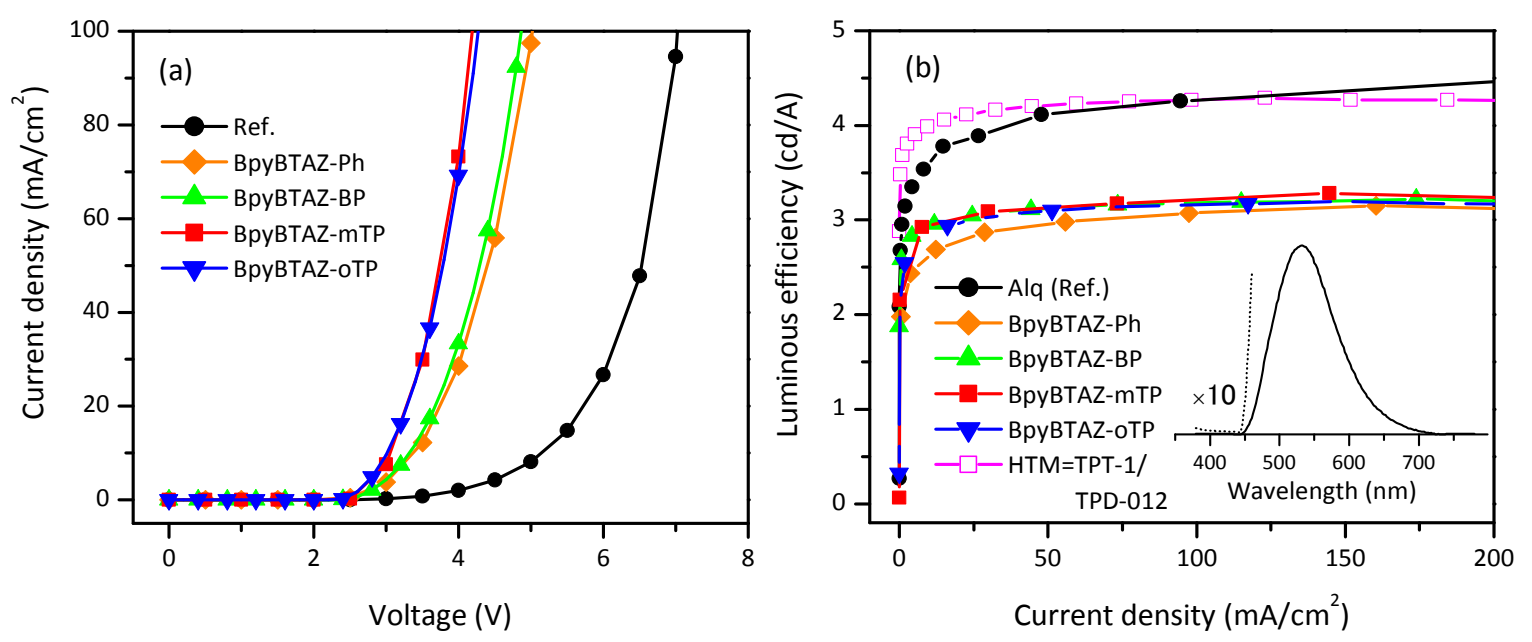

Figure 6. (a) Current density-voltage $(J-V)$ and (b) luminous efficiency-current density $(\eta-J)$ curves of devices with each BpyBTAZ. The inset in panel (b) shows the EL spectrum of the BpyBTAZ-mTP device and the dotted line is a $\times 10$ magnification. 


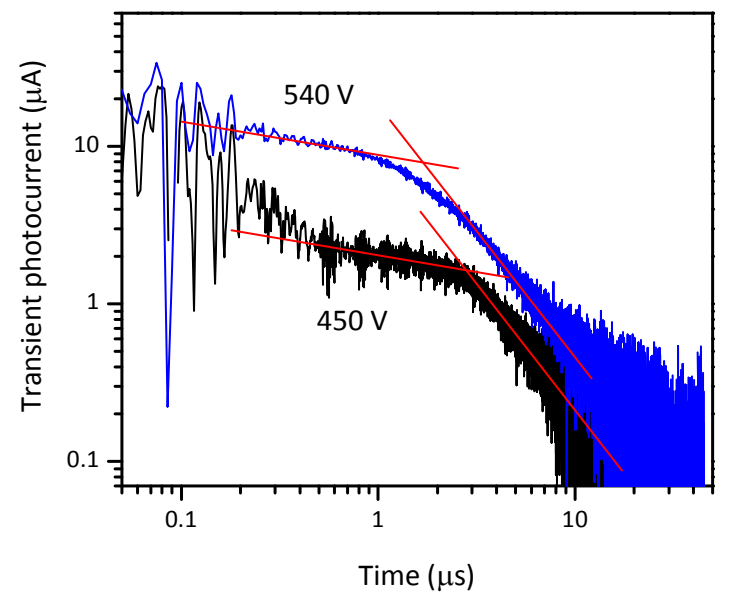

Figure 7. Transient photocurrent curves of TOF measurement of BpyBTAZ-mTP at the applied voltages of 450 and $540 \mathrm{~V}$. Red straight lines are drawn to help determine the transit time. 


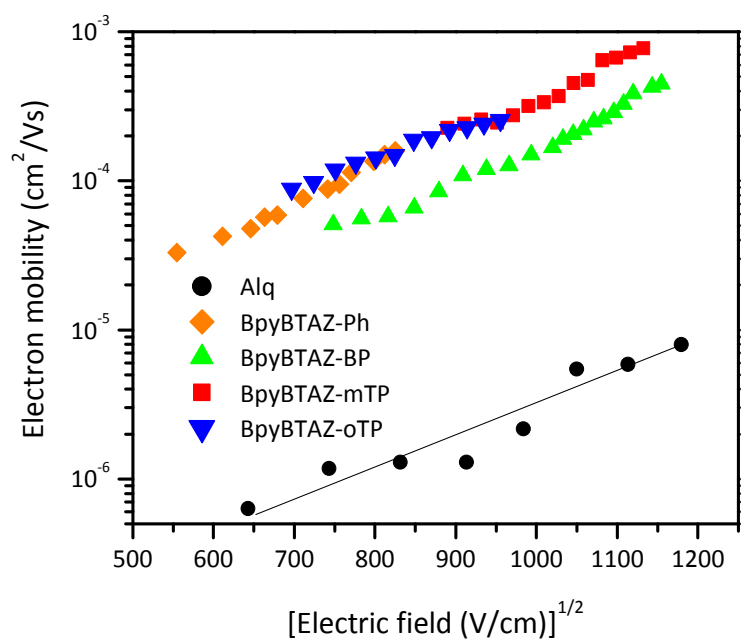

Figure 8. Electron mobilities of BpyBTAZ compounds as a function of square root of electric field. Data for Alq were referred from the literature by Murata (see text).

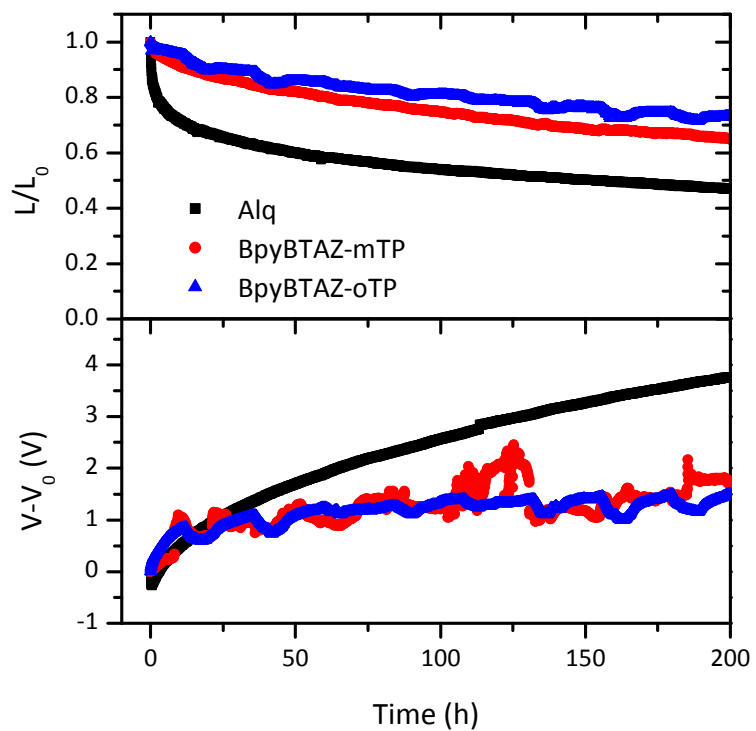

Figure 9. Luminance and voltage changes under constant current density operation at 50 $\mathrm{mA} / \mathrm{cm}^{2}$ for devices with different ETMs. The device structure is the same as the test OLED shown in Fig. 2. The devices were encapsulated by a glass cap with fresh desiccant using UV glue in an inert glove box $\left(\mathrm{O}_{2}<5 \mathrm{ppm}\right.$, dewpoint $\left.<-50{ }^{\circ} \mathrm{C}\right)$. 


\section{Supporting Information}

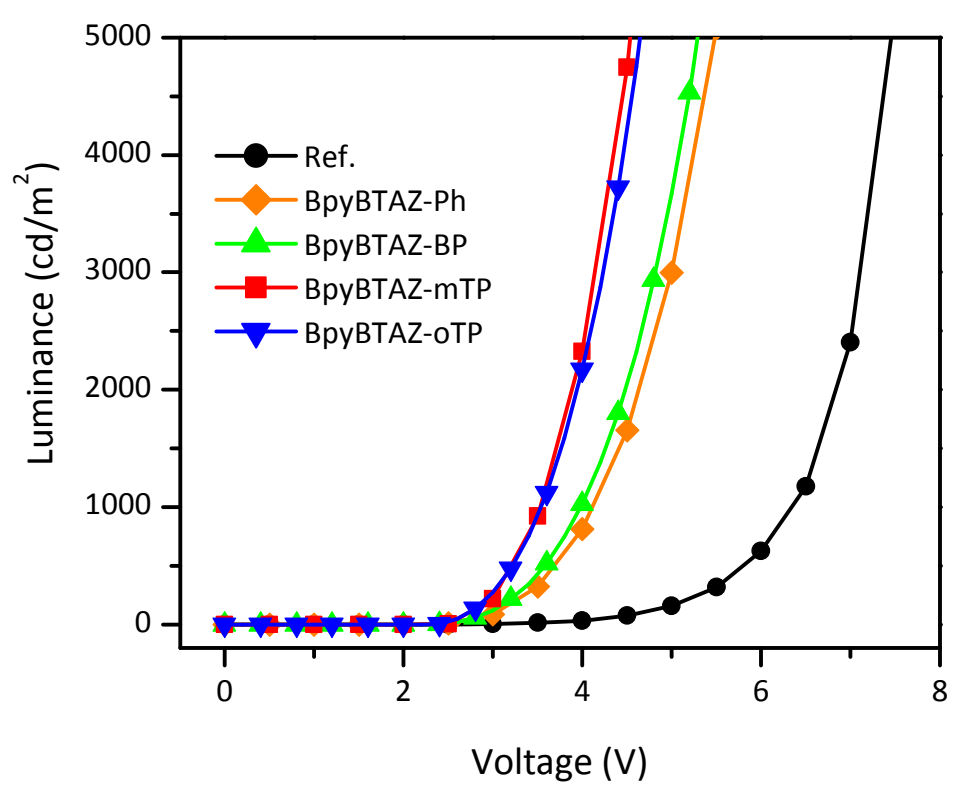

Fig. S1. Luminance-voltage characteristics of the devices shown in Fig. 6a.

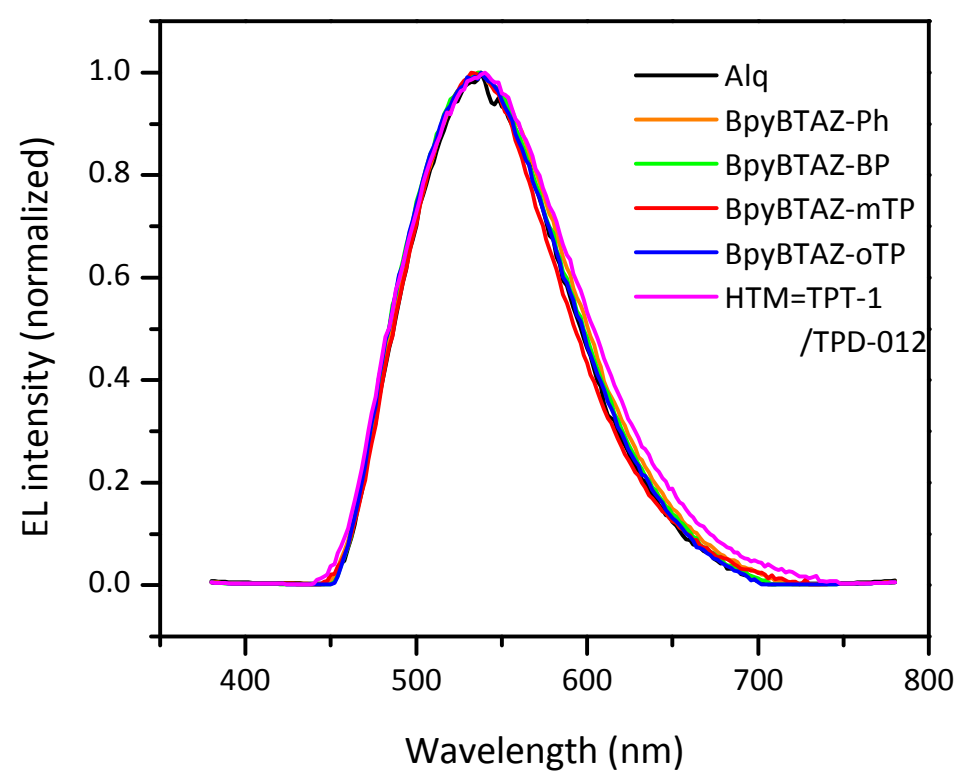

Fig. S2. EL spectra of the devices shown in Fig. $6 \mathrm{~b}$. 

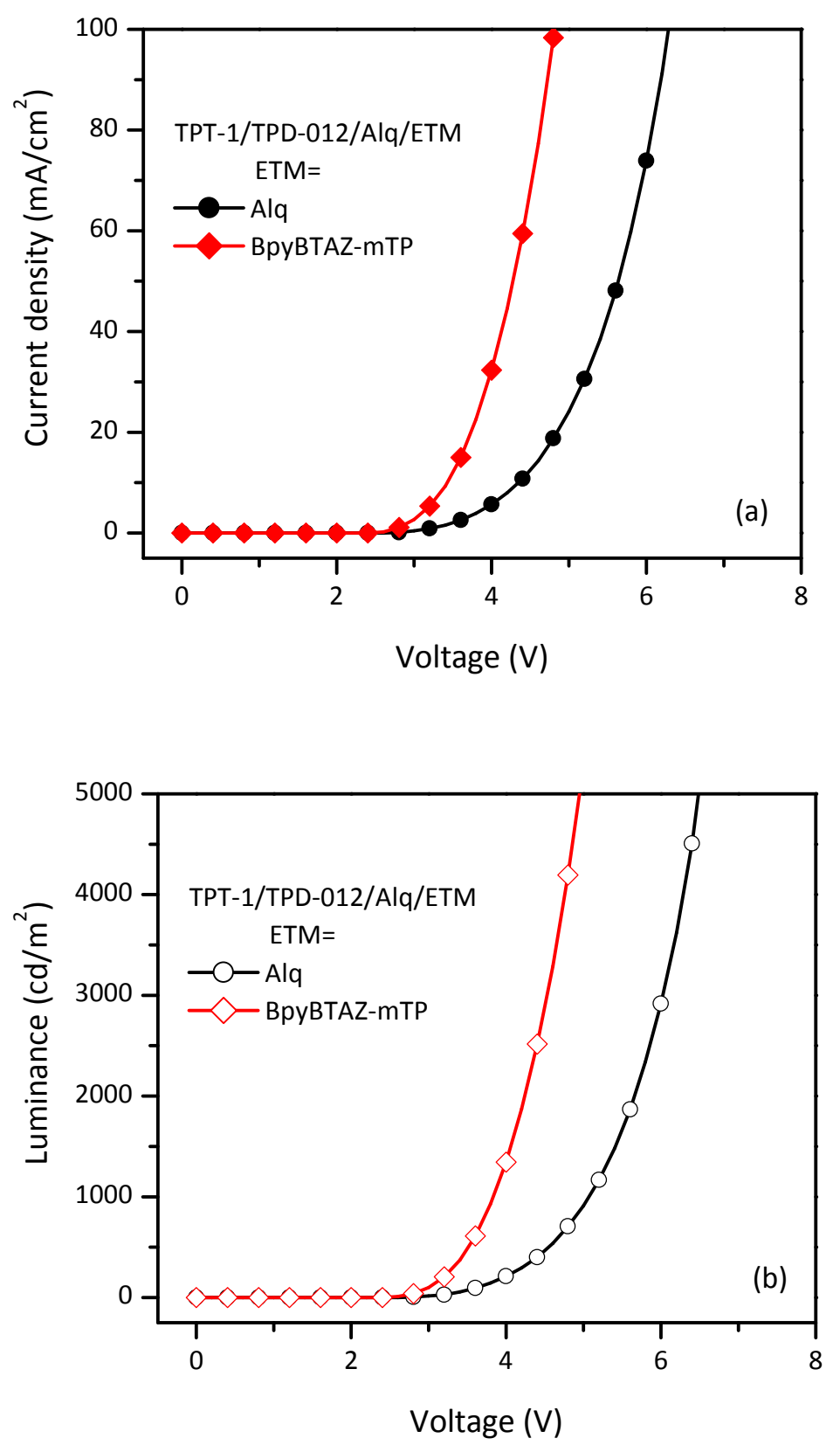

Fig. S3. (a) J-V and (b) luminance - voltage characteristics of the devices using a set of TPT-1 and TPD-012 as hole transporting layer. Alq or BpyBTAZ-mTP was used as the ETM. 

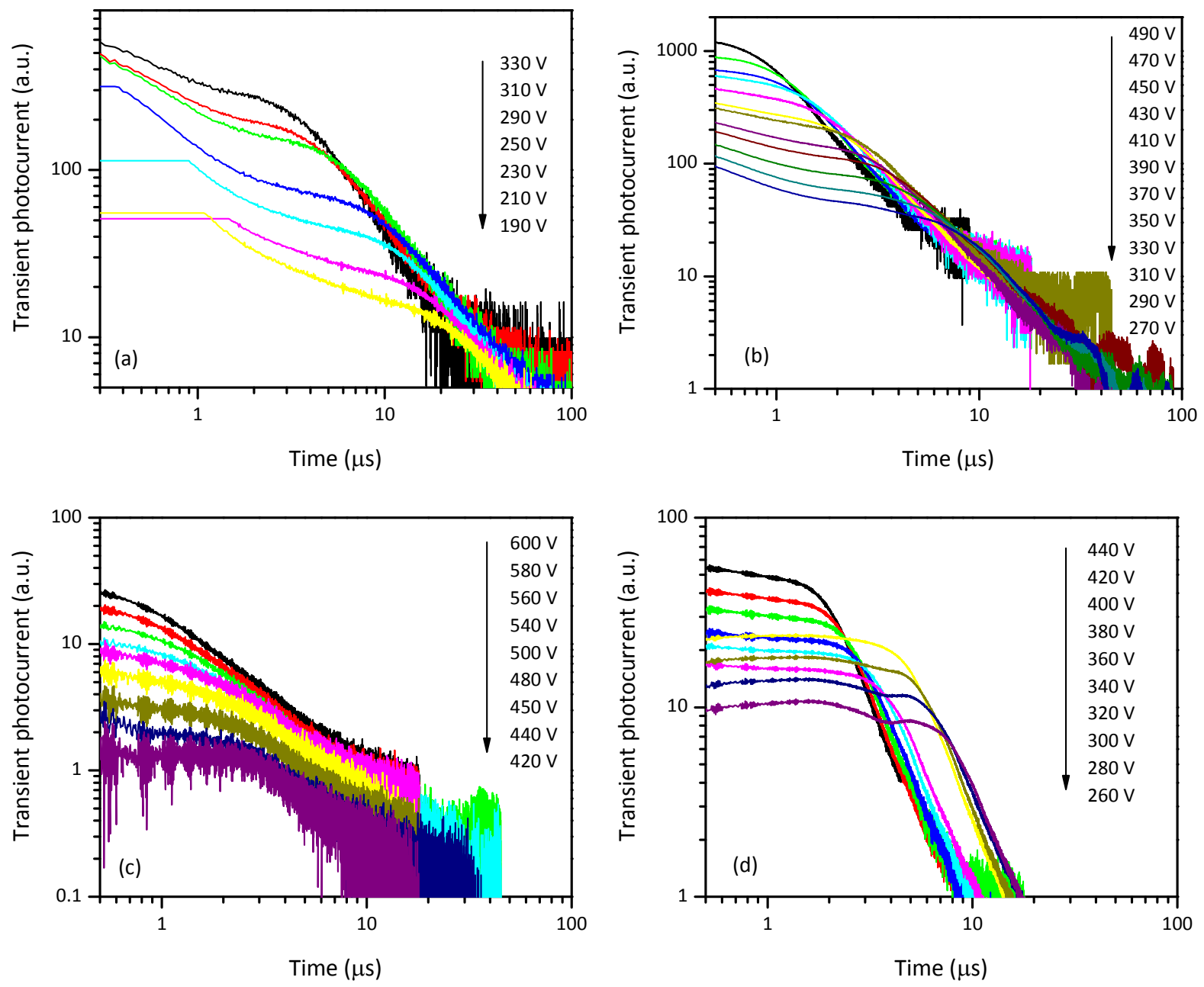

Fig. S4. Transient photocurrent responses for each material: (a) BpyBTAZ-Ph, (b) -BP, (c) mTP, (d) -oTP. Thicknesses of each test cell are, respectively, $4.45 \mu \mathrm{m}$ for $-\mathrm{Ph}, 3.65 \mu \mathrm{m}$ for -BP, $5.20 \mu \mathrm{m}$ for $-\mathrm{mTP}$, and $5.15 \mu \mathrm{m}$ for $-\mathrm{oTP}$. 